\title{
Investigation on the optical, spectral, electrical, mechanical, and laser damage threshold studies of bis (4-acetylanilinium) tetrachloridozincate (B4ATCZ) crystal
}

\author{
M. Suriya ${ }^{1}$, M. Manimaran ${ }^{1}$, B. Milton Boaz ${ }^{1}$, and K. Sakthi Murugesan ${ }^{1, *}$ (B) \\ ${ }^{1}$ Department of Physics, Presidency College, University of Madras, Tamil Nadu, Chennai 600005, India
}

Received: 9 October 2020

Accepted: 6 January 2021

Published online:

29 January 2021

(C) The Author(s) 2021

\begin{abstract}
An efficient semi-organic nonlinear optical bis (4-acetylanilinium) tetrachloridozincate $\left[\left(\mathrm{C}_{8} \mathrm{H}_{10} \mathrm{NO}\right)_{2} \mathrm{ZnCl}_{4}\right]$ (B4ATCZ) single crystal was synthesized and successfully grown by the slow evaporation method. The single-crystal $\mathrm{X}$-ray diffraction data confirm that B4ATCZ crystallized into an orthorhombic crystal system (Cmca). The UV-Vis-NIR transmittance spectrum was taken to assess the optical transmission, cut-off wavelength, and bandgap energy. The TG-DSC investigation ensures that the B4ATCZ is stable up to $235^{\circ} \mathrm{C}$. The mechanical behavior of the B4ATCZ compound was determined by Vickers Microhardness analysis. The surface laser-induced damage threshold value of the grown B4ATCZ crystal was endowed to be $19.78 \mathrm{GW} / \mathrm{cm}^{2}$ on testing with $1064 \mathrm{~nm} \mathrm{Nd}$ : YAG laser radiation. The positive photoconductive properties and charge transport mechanism of B4ATCZ crystal were analyzed through photoconductivity and dielectric studies. The electron excitation and lifetime measurements of the molecules in the B4ATCZ crystal were studied by fluorescence spectral analysis. The HOMO-LUMO analysis evidently interprets the occurrence of $\mathrm{N}-$ $\mathrm{H} \cdots \mathrm{O}$ and $\mathrm{N}-\mathrm{H} \cdots \mathrm{Cl}$ intermolecular hydrogen bonds influencing the charge transfer in the system. The electrostatic potential surface reveals the possible sites for hydrogen bonding electrophilic and nucleophilic interactions. Thirdorder nonlinear optical activity evaluated by the Z-scan measurements indicates the self-focusing and reverse saturable absorption in the crystal. The aforesaid results affirm that the metal-organic B4ATCZ is a potential material for optoelectronic and nonlinear optical device applications.
\end{abstract}

Address correspondence to E-mail: ksakthimurugesan2492@gmail.com 


\section{Introduction}

In recent scenario, material scientists focused their predominant research interest in developing novel semi-organic nonlinear optical materials due to their overwhelming and widespread applications in ultrafast signal processing, optical switching, wave mixing, electro-optical modulation, and generation of higher harmonic frequencies [1, 2]. Semi-organic crystals have gained large-scale interest due to the combined properties of both organic and inorganic materials for efficient device fabrications. This class of crystalline materials also possesses higher thermal and mechanical stability along with transparency and high molecular polarizability by the stoichiometrically coupled organic compound within the inorganic ligand [3, 4]. Moreover, such kind of semi-organic materials exhibits large macroscopic nonlinear optical effects compared to organic and inorganic materials due to the presence of $\pi$-delocalized intermolecular charge transfer (ICT) configuration system [5,6]. The organic base material of 4-acetylaniline is a strong hydrogen bond acceptor in nature and it is easily bonded to the halogenate metals to form stable crystal structures [7-9]. Furthermore, anilinium derivatives with ion combinations were utilized in electroluminescence, electrical conduction, rechargeable batteries, and anti-corrosion applications. In this way, aniline and its derivative-based research have attracted attention in the development of nonlinear optical chromophores [10-12]. In the metal-organic hybrid crystal structure of B4ATCZ, the hydrogen chloride transfers the proton between the organic ligand and metal complex. The B4ATCZ crystal system is stabilized by the strong intermolecular hydrogen bond of $\mathrm{N}-\mathrm{H} \cdots \mathrm{Cl}$ and the cation-cation van der Waals $\mathrm{N}-\mathrm{H}$...O interactions established by aromatic $\pi$-stacking. Generally, the centrosymmetric crystal structure exhibits the third harmonic generation (THG) and find a wide range of applications in holographic memory devices, integrated optics, optical communication networks, optical signal processing, and optical power limiting for sensor production from high intense laser pulses in the latest optical technology [5, 13-15]. Bis (4acetylanilinium) tetrachloridozincate is an efficient metal-organic hybrid material possessing a higher nonlinear optical coefficient and a large transmittance window influenced by the $\mathrm{d}^{10}$ configuration of metal ions. This strong metal-ligand bond is prominent for larger optical susceptibility and larger molecular polarizability which are prerequisites for third-order NLO response. Also, these properties of semi-organic materials promote their use in photonic and optoelectronic switching devices which form the basis for future optical systems [16, 17]. Considering the nonlinear optical properties of 4-acetylanilinium derivatives, a successful attempt has been made to grow 4-acetylanilinium derivative single-crystal bis (4acetylanilinium) tetrachloridozincate $\left[\left(\mathrm{C}_{8} \mathrm{H}_{10} \mathrm{NO}\right)_{2}\right.$ $\mathrm{ZnCl}_{4}$ ] (B4ATCZ) by the slow solvent evaporation method. Amine Fersi et al. [9, 18] have reported the crystal structure, thermal and dielectric properties of B4ATCZ crystal; there is no report on the growth of this material for vital technological applications. In continuation with that, we present our results on growth, solubility, UV-Visible transmission, Vickers microhardness test, fluorescence and lifetime measurement, photoconductivity, laser damage threshold, electrostatic potential surface analysis, and Frontier molecular orbital studies of B4ATCZ crystal. Since the crystal structure of B4ATCZ has been identified as a (Cmca) centrosymmetric space group, we have aimed to study the third-order NLO properties of the grown crystal. As far as we know, the studies mentioned here have been reported for the first time and the results are discussed in detail in this paper.

\section{Experimental detail}

\subsection{Bulk crystal growth and solubility of B4ATCZ}

The B4ATCZ compound was synthesized by analar reagent grade 4 -acetylaniline (99\%), anhydrous zinc chloride (99.99\%), and concentrated $\mathrm{HCl}$ aqueous solution (38\%) in the molar ratio 2:1:2 utilizing deionized water $(99.99 \%)$ as a solvent. The chemical reaction scheme and optimized molecular geometry of the grown B4ATCZ compound are shown in Fig. 1. The prepared solution was stirred well for $12 \mathrm{~h}$ using a stirrer to yield a homogeneous mixture. The solution was then filtered and allowed for evaporation subsequently at ambient temperature. In the slow solvent evaporation method, the solubility of the material and the temperatures are the significant factors in growing bulk size and good optical quality single crystals [19]. The solubility of the synthesized 
Fig. 1 Chemical reaction with the optimized molecular structure of B4ATCZ compound

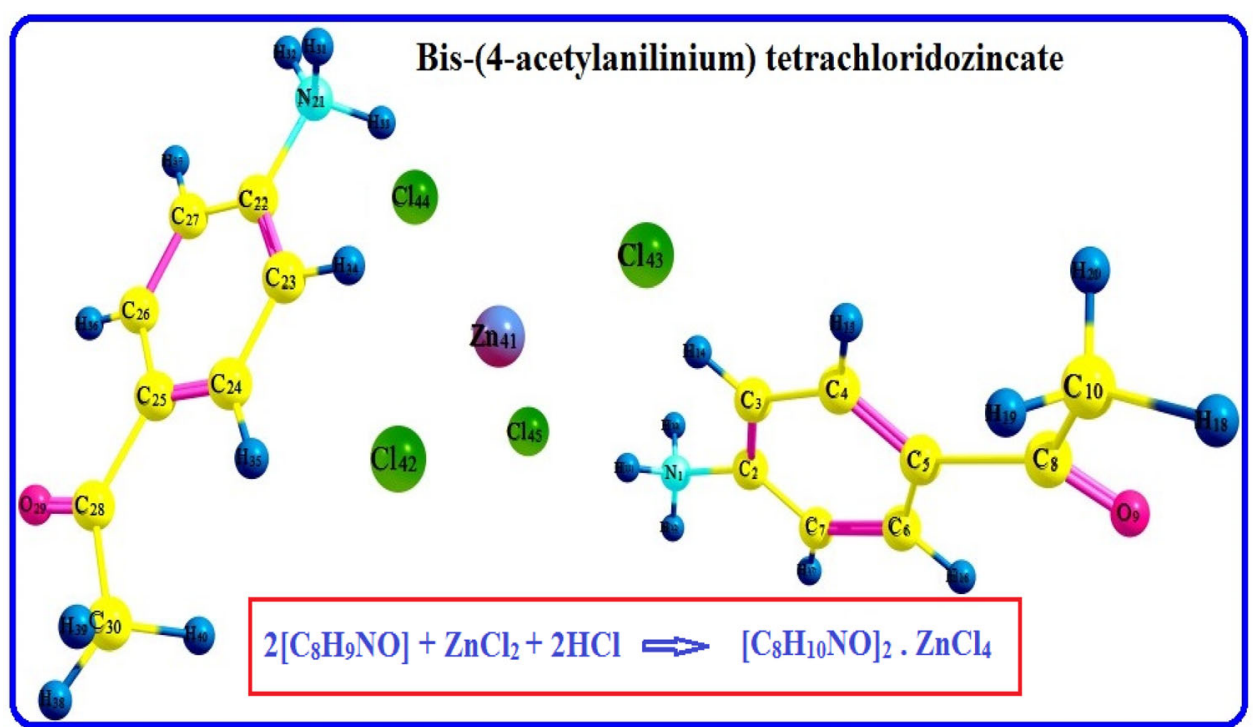

B4ATCZ in deionized water was determined as a function of temperatures in the range $30-50{ }^{\circ} \mathrm{C}$ with an interval of $5^{\circ} \mathrm{C}$ using a constant temperature bath with a control accuracy of $\pm 0.01{ }^{\circ} \mathrm{C}$. The synthesized salt was weighed and added gradually to the water solvent to obtain saturation. The concentration of the solute was then assessed gravimetrically for different temperatures. From the solubility curve of B4ATCZ (Fig. 2), it is observed that the solubility increases linearly with all the temperatures. Therefore, the B4ATCZ exhibits a positive solubility gradient with endothermic reaction, favoring the growth of large-

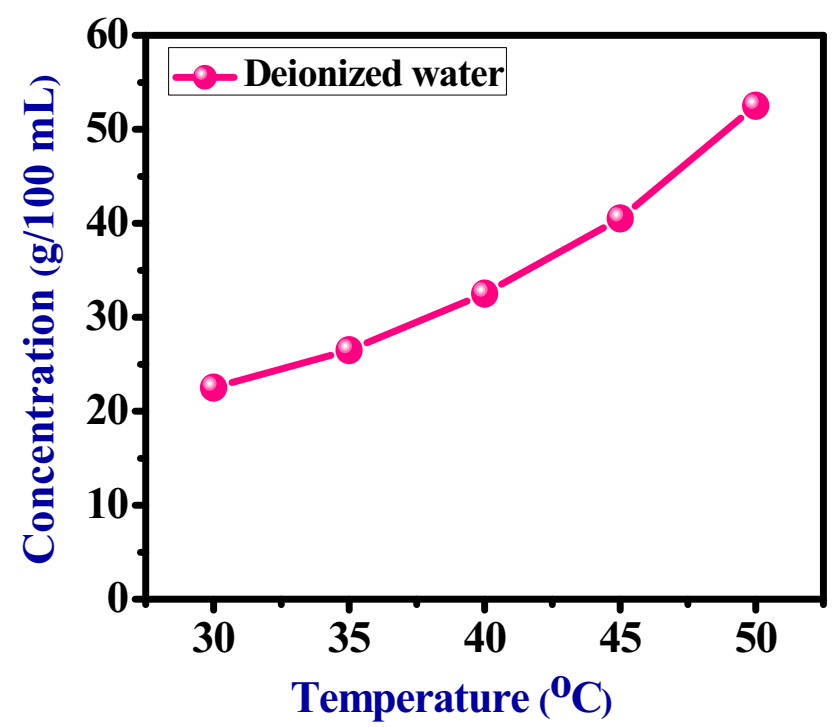

Fig. 2 Solubility curve of B4ATCZ in water solvents at various temperatures size single crystals from the solution. The solubility of B4ATCZ was found to be $26.56 \mathrm{~g} / 100 \mathrm{~mL}$ (in water) at $35{ }^{\circ} \mathrm{C}$. In accordance with the solubility data, the supersaturated solution of B4ATCZ was prepared and stirred continuously for thorough mixing. Then the final solution was filtered using Chemex filter paper and kept in a constant temperature water bath at $35{ }^{\circ} \mathrm{C}$ with an accuracy of $\pm 0.01{ }^{\circ} \mathrm{C}$. As a result of constant evaporation, a nonhygroscopic and hexagonal-shaped brown-colored single crystal with dimension $20 \times 12 \times 7 \mathrm{~mm}^{3}$ was harvested from the mother solution over a growth period of 45 days. The grown B4ATCZ crystal morphology identified and indexed by Enraf Nonius CAD 4 single-crystal X-ray diffractometer reveals that the flat face $\left(\begin{array}{lll}1 & 0 & 0\end{array}\right)$ was along the $b$-axis. The other predominant planes in the B4ATCZ crystal were indexed as (0 10$),(0-10)$, ($211),\left(\begin{array}{l}2-1-1 \\ 2\end{array}\right),\left(\begin{array}{lll}1 & 0 & 2\end{array}\right)$, and $\left(\begin{array}{lll}-1 & 0 & -2\end{array}\right)$. The asgrown B4ATCZ single-crystal photograph and morphology are shown in Fig. 3a and b, respectively.

\subsection{Methods of characterization}

The grown metal-organic hybrid bis (4-acetylanilinium) tetrachloridozincate $\left[\left(\mathrm{C}_{8} \mathrm{H}_{10} \mathrm{NO}\right)_{2} \mathrm{ZnCl}_{4}\right]$ single crystals were subjected to various characterization methods such as X-ray diffraction, optical, thermal, mechanical, laser damage threshold, electrical, luminescence, nonlinear optical and also quantum computational studies. The single-crystal X-ray diffraction of B4ATCZ was carried out using BRUKER KAPPA APEXII CCD single-crystal X-ray 


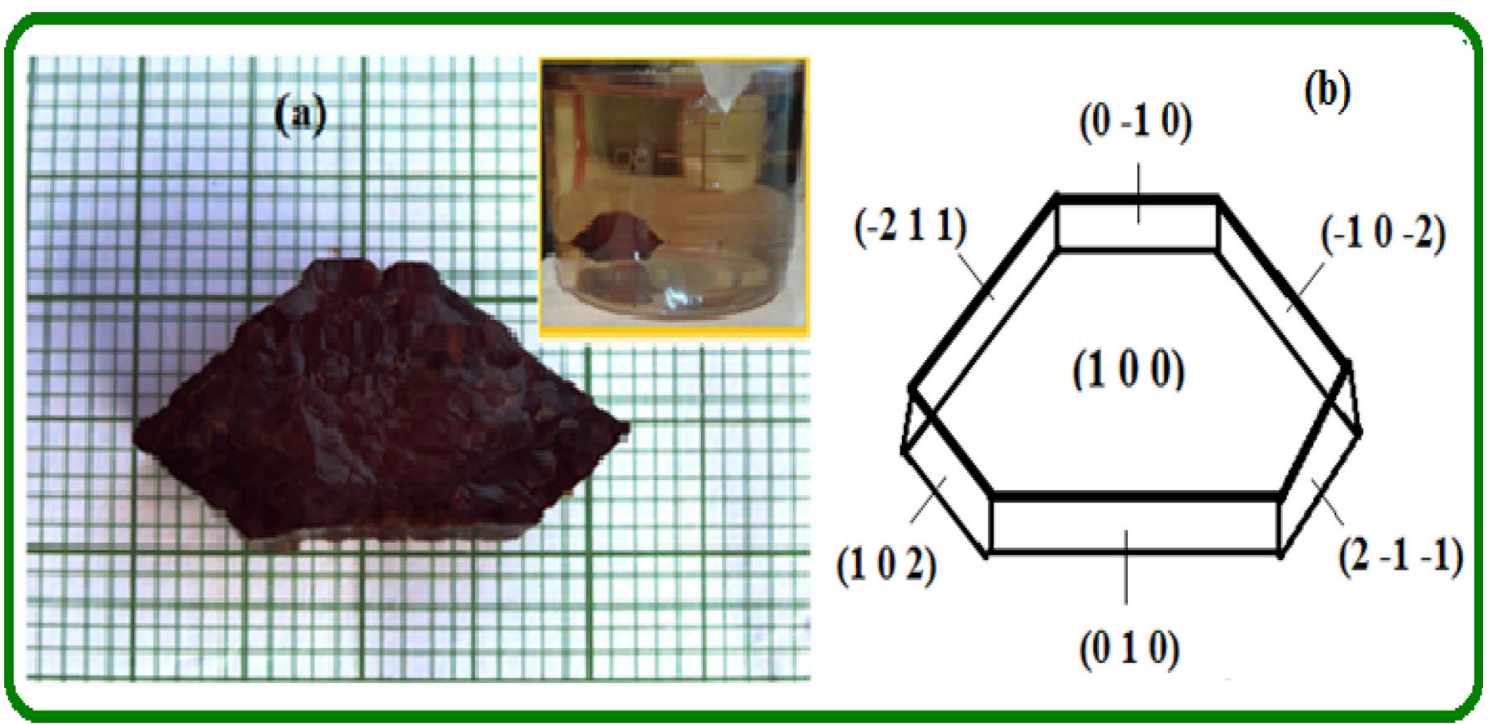

Fig. 3 a Photograph and, b morphology of the as-grown B4ATCZ single crystal

diffractometer with Mok $\alpha(\lambda=0.71073 \AA)$ radiation. The optical transmittance of the B4ATCZ was studied employing the UV-1800 SHIMADZU spectrophotometer in the wavelength of 200 to $800 \mathrm{~nm}$. Thermogravimetric and Differential Scanning Calorimetric analysis were performed on the title B4ATCZ compound utilizing Netzsch STA 409 Simultaneous Thermal Analyzer. The mechanical hardness of the B4ATCZ compound was measured by ECONOMET Vickers microhardness instrument fitted with pyramidal indentor. The surface laser damage threshold of the grown B4ATCZ single crystal was determined utilizing Q-switched $\mathrm{Nd}$ : YAG Laser $(1064 \mathrm{~nm})$. The dielectric aspect of the metal-organic B4ATCZ compound was assessed by HIOKI (3532-50) Hi-Tester LCRi dielectric meter. The photoconductive response on the B4ATCZ single crystal was performed by two probe methods at room temperature using picoammeter (Keithley-480) as a function of dc electric applied field. The fluorescence and lifetime studies were done with the support of the PERKIN ELMER LS-45 and FLUOROCUBE spectrofluorometer, respectively. The optimized molecular structure, Frontier molecular orbital energies, and electrostatic potential were computed by the DFT method using the B3LYP level, Gaussian 09 program package with $6-311++\mathrm{G}(\mathrm{d}, \mathrm{p})$ basis set [20-22]. Third-order nonlinear optical parameters of the grown bis (4-acetylanilinium) tetrachloridozincate crystal were qualitatively evaluated using a 532 nm Diode-Pumped continuous-wave Nd: YAG laser.

\section{Results and discussion}

\subsection{Single-crystal X-ray diffraction analysis}

The single-crystal X-ray diffraction results reveal that the grown bis (4-acetylanilinium) tetrachloridozincate belongs to the orthorhombic crystal system with the space group (Cmca). The calculated unit cell parameters $a=15.63 \AA, b=19.51 \AA, c=13.80 \AA, \alpha=\beta$ $=\gamma=90^{\circ}$, and volume $(V)=4162 \AA^{3}$ well agree with the reported values [18].

\subsection{Linear optical analysis}

\subsubsection{Optical transmittance studies}

For nonlinear optical crystal, the lower optical absorption of light in the entire UV-Vis region and wider transparency window over the near-infrared wavelength range are the required parameters in providing information about its optoelectronic transitions. In general, $\mathrm{UV}-\mathrm{V}$ is spectroscopic studies are employed to know about the electronic structure of the materials at the molecular level, because the ultraviolet-visible absorption spectrum evidences the promotion of electrons to excited energy state [23]. The linear transmittance spectrum for a well-polished B4ATCZ single crystal of $2 \mathrm{~mm}$ thickness recorded in the wavelength of $200-800 \mathrm{~nm}$ is shown in Fig. 4a. The obtained optical spectrum reveals $59 \%$ of transmission in the entire UV-Vis and IR regions with a lower cut-off wavelength around $326 \mathrm{~nm}$. The lower 


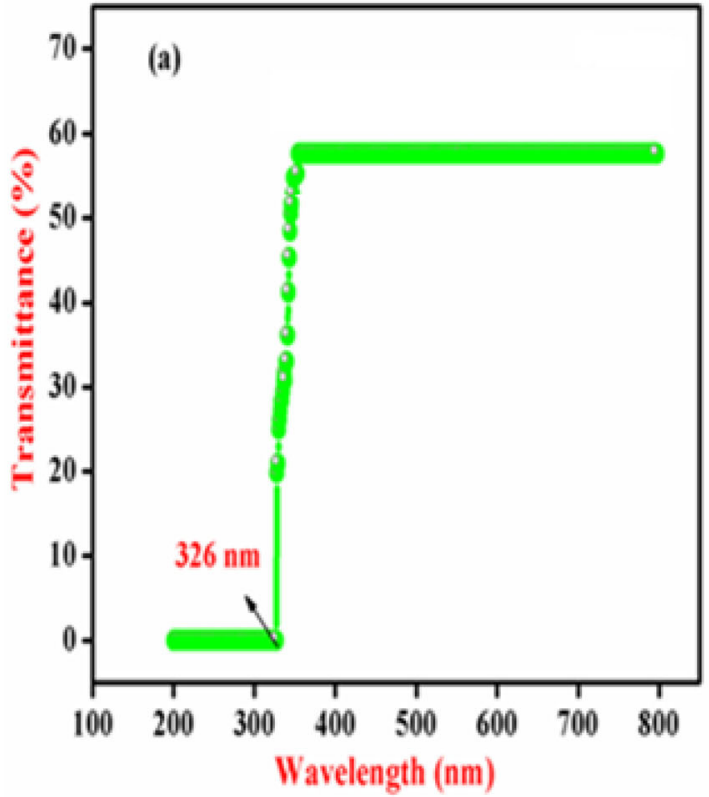

Fig. 4 a UV-Vis transmission profile and, b Tauc's plot of B4ATCZ

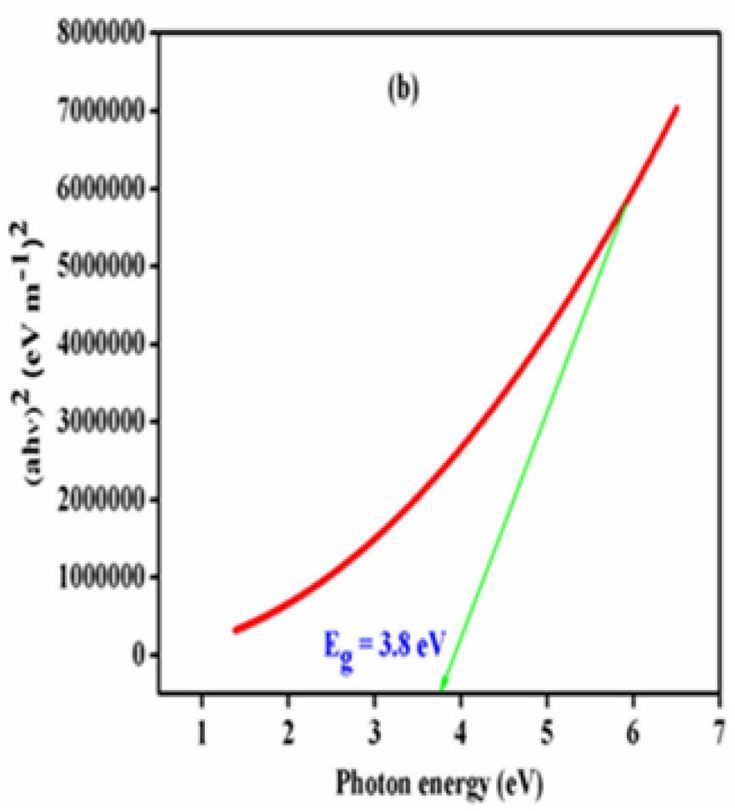

optical absorption in the region below $326 \mathrm{~nm}$ was owing to the promotion of electrons from nonbonding (n) state to antibonding $\left(\pi^{*}\right)$ state $\left(n \rightarrow \pi^{*}\right.$ electronic transition) due to the excitation of carboxyl $(\mathrm{C}=\mathrm{O})$ group in the B4ATCZ crystal [24]. The appearance of the brown color of the compound may be owing to the amino $\left(\mathrm{NH}_{3}{ }^{+}\right)$chromophores present in the B4ATCZ crystals, which limit the transparency up to $326 \mathrm{~nm}$. The minimum cut-off wavelength with widespread optical transmission window extends the applications of B4ATCZ towards the fabricating photonics and optoelectronic devices and also the generation of the third harmonics [25, 26]. The optical absorption coefficient $(\alpha)$ and electronic bandgap energy $\left(E_{\mathrm{g}}\right)$ were evaluated from the transmission spectrum and the Tauc's plot using the relations [27],

$\alpha=\frac{2.303}{t} \log \left(\frac{1}{T}\right)$

$(\alpha h v)^{2}=A\left(E_{\mathrm{g}}-h v\right)^{s}$,

where ' $T$ ' is the transmittance spectrum (\%) and ' $t$ ' denotes the thickness of the B4ATCZ crystal $(2 \mathrm{~mm})$, ' $h$ ' is the Planck's constant, ' $v$ ' is the incident photons frequency, ' $A$ ' is a constant of the material, and ' $s$ ' is the optical transition number indicating the indirect (2) and direct (1/2) optical transitions [28]. As these materials possess a direct optical transition, the Tauc's plot (Fig. $4 \mathrm{~b}$ ) was drawn between $(\alpha h v)^{2}$ versus photon energy $(h v)$. By extrapolating the linear portion of the plot with zero absorption, the electronic bandgap energy $\left(E_{\mathrm{g}}\right)$ was experimentally estimated as $3.8 \mathrm{eV}$ [29]. Theoretically, ' $E_{\mathrm{g}}$ ' of B4ATCZ crystal was verified using Planck's equation, $\left[E=h_{\mathrm{c}} / \lambda_{\mathrm{c}}\right]$ where ' $\lambda_{\mathrm{c}}$ ' is the lower cut-off wavelength $(326 \mathrm{~nm})$ of the grown compound. The electronic bandgap energy was found to be $3.8 \mathrm{eV}$ which strictly coincides with the experimental bandgap value obtained. The minimum cut-off wavelength $(326 \mathrm{~nm})$ with a large optical bandgap energy $(3.8 \mathrm{eV})$ may lead to enhanced optical conductivity of the crystal with the absorption of an optical photon in a particular range of wavelengths, which demonstrates the material has the admirable dielectric properties [26].

\subsubsection{Determination of optical parameters}

The fulfillment of the material was effectively sustained by the optical behaviors, which decides the usefulness of the material for optical-electronic, optical switching, and various nonlinear optical device fabrications [30, 31]. The dependence of the absorption coefficient $(\alpha)$ along with the larger photon energy $(h v)$ supports to analyze the band structure and the types of the electrons transition at the molecular level. The valuable optical parameters were also evaluated utilizing the following 
theoretical formulae [32]. The linear absorption coefficient ' $\alpha$ ' associated with the extinction coefficient ' $k$ ' is given by

$K=\frac{\alpha \lambda}{4 \pi}$.

The reflectance $(R)$ and refractive index $(\mu)$ interrelated to the linear absorption coefficient are estimated from the relations:

$R=1 \pm \frac{\sqrt{1-\exp (-\alpha t)+\exp (\alpha t)}}{1+\exp (-\alpha t)}$

$\mu=-\left\{\frac{(R+1) \pm \sqrt{-3 R^{2}+10 R-3}}{2(R-1)}\right\}$.

The variations of the reflectance $(R)$ and the extinction coefficient $(K)$ with the higher photon energy shown in Fig. $5 \mathrm{a}$ and $\mathrm{b}$ have demonstrated normal linear optical properties. From Fig. $5 c$, it is clear that the twain reflectance and extinction coefficient fully depend on the linear absorption coefficient. The lower values of reflectance and extinction coefficient are supporting the higher transmittance of the grown B4ATCZ crystal for particular applications in nonlinear optics [33]. Generally, the refractive index decides how much light is refracted or bent, when it enters into the material. Since the inherent efficiency of the device also relies on the incident photon energy (hv), by exactly adjusting the ' $h v^{\prime}$ values, the desired material for optoelectronic device fabrications can be easily obtained. Figure $5 d$ represents the variation of the linear refractive index $(\mu)$ with the wavelength. It is clearly observed that the refractive index gradually decreases with the increase of wavelength. The refractive index of the B4ATCZ was found to be 1.662 at the wavelength of $487 \mathrm{~nm}$ and this low value of ' $\mu$ ' highlights that the B4ATCZ crystal shows the regular dispersion behavior. The lower refractive index with higher optical transparency of B4ATCZ crystal in the entire UV-Vis region erects it as a potential material for the optical components like resonators, reflectors,
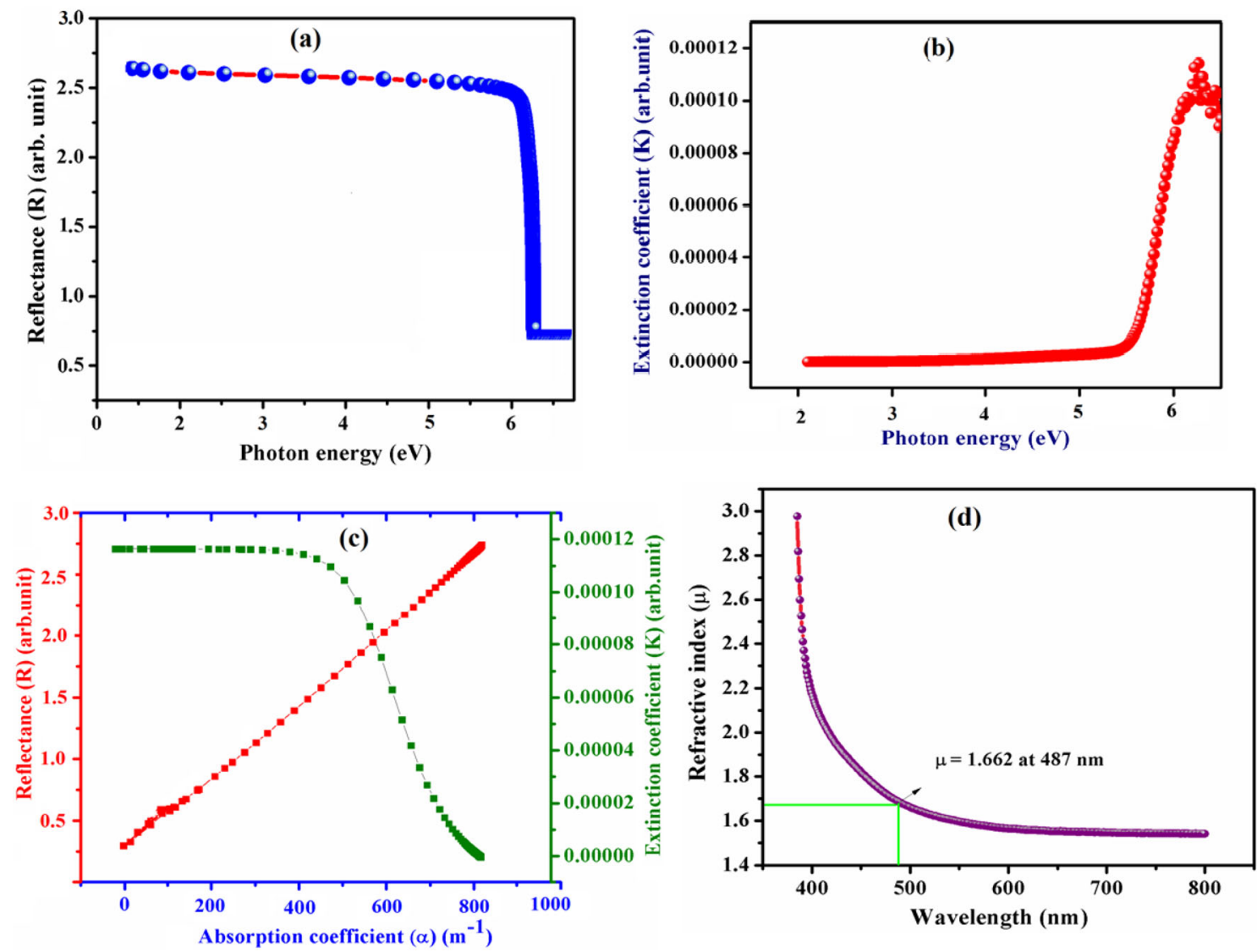

Fig. 5 a The plot of reflectance $(R)$ vs. photon energy $(h v)$, b variation of extinction coefficient $(K)$ with ' $h v$ ', $\mathbf{c}$ variation of ' $R$ ' and ' $K$ ' with linear absorption coefficient ' $\alpha$ ' and, $\mathbf{d}$ the linear refractive index $(\mu)$ with the wavelength of B4ATCZ crystal 
signal filters, and anti-reflective coating in solar thermal devices [32-34].

The photonic response of optical conductivity $\left(\sigma_{\mathrm{opt}}\right)$ of the crystal depends upon the irradiation of the light and it is interrelated to the absorption coefficient $(\alpha)$, refractive index $(\mu)$ of the material, and the speed of light $(c)$ as

$\sigma_{\mathrm{opt}}=\frac{\mu \alpha c}{4 \pi}$.

The electrical conductivity $\left(\sigma_{\text {ele }}\right)$ is related to the optical conductivity of the B4ATCZ crystal by

$\sigma_{\mathrm{ele}}=\frac{2 \lambda \sigma_{\mathrm{opt}}}{\alpha}$

From Fig. 6a, it is evident that the optical conductivity $\left(\sigma_{\text {opt }}\right)$ gradually increases with incident photon energy ( $h v)$ possessing higher order of magnitude $\left(10^{9}(\Omega \mathrm{m})^{-1}\right)$, thereby confirming the high photo- tunable behavior of the material [32]. From Figs. 5c and $6 \mathrm{a}$, it is assured that the low value of extinction coefficient $\left(10^{-5}\right)$ and electrical conductivity $(1.0 \times$ $\left.10^{13}(\Omega \mathrm{m})^{-1}\right)$ reveals the semiconducting nature of the material. Thus, the B4ATCZ compound could be more convenient for device applications in computing ultrafast optical data. The electric susceptibility $\left(\chi_{c}\right)$ could be calculated by the elucidated optical constants from the relation [35]:

$\chi_{\mathrm{c}}=\frac{\mu^{2}-K^{2}-\varepsilon_{\mathrm{o}}}{4 \pi}$

where ' $\varepsilon_{0}$ ' is the constant of dielectric in the absence of any contribution from free carriers. The determined electric susceptibility $\left(\chi_{c}\right)$ value is 0.1274 at $\lambda=$ $487 \mathrm{~nm}$ (Fig. 6b). The real $\left(\varepsilon_{\mathrm{r}}\right)$ and imaginary $\left(\varepsilon_{\mathrm{i}}\right)$ parts of dielectric constant were determined based on
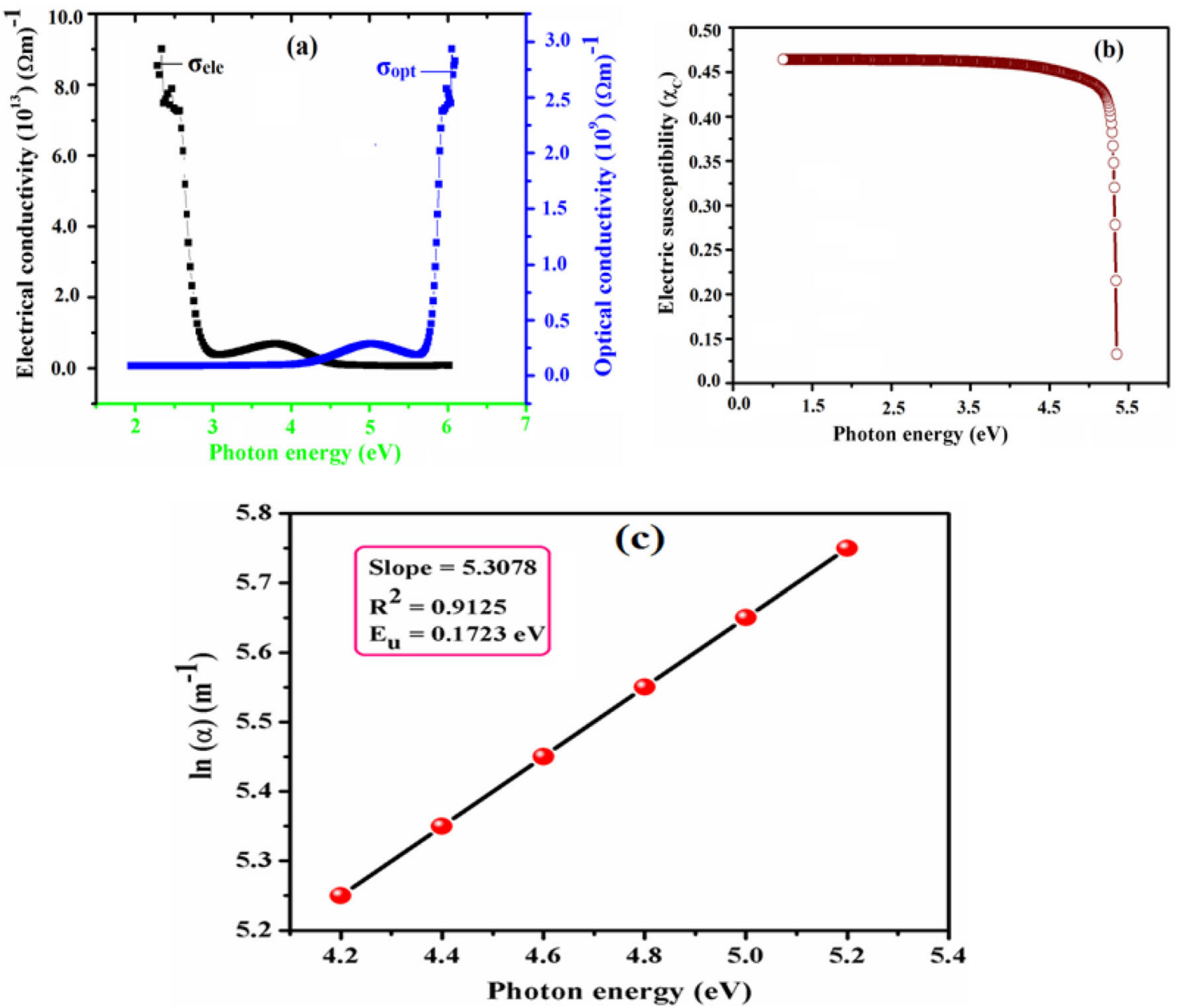

Fig. 6 a Variation of optical conductivity and electrical conductivity vs. photon energy $(h v)$, b electrical susceptibility vs. ' $h v$ ', c the plot of $\ln (\alpha)$ vs. ' $h v$ ' of the B4ATCZ crystal 
refractive index and extinction coefficient from the relations:

$\varepsilon_{\mathrm{r}}=\mu^{2}-K^{2} \quad$ and $\quad \varepsilon_{\mathrm{i}}=2 \mu K$.

The real and imaginary part values of the dielectric constants at the wavelength $(\lambda)=487 \mathrm{~nm}$ are found to be 2.4180 and $3.4265 \times 10^{-6}$, respectively. Therefore, the linear optical constants of a material like optical bandgap energy and extinction coefficient are absolutely important to investigate the material's capability in optoelectronic applications [36].

\subsubsection{Urbach energy}

The linear absorption coefficient $(\alpha)$ is depicted in terms of an exponential edge region by Urbach relationship as [37];

$\alpha=\alpha_{o} \exp \left(\frac{h v}{E_{\mathrm{u}}}\right)$,

where ' $\alpha_{0}$ ' is a constant, and ' $E_{\mathrm{u}}$ ' is the Urbach energy, which supports the formation of depth-of-tail levels elongating into the forbidden electronic bandgap below the absorption edge. The Urbach energy plot illustrated as the function of high photon energy (hv) versus the logarithm of the absorption coefficient $\ln (\alpha)$ is shown in Fig. 6c. From the linear plot, the slope value was observed at 5.3078. The reciprocal of the slope of the linear portion exhibits the value of Urbach energy. The estimated Urbach energy value of the B4ATCZ crystal is found to be 0.1723 and this low value of ' $E_{\mathrm{u}}$ ' reveals that the grown crystal is highly crystalline in nature with the negligible structural defect [38].

\subsection{TG and DSC analyses}

The thermal investigation is one of the significant characterizations for practical device fabrication and also it particularly provides information about a thermal decomposition, phase transitions, stability, and melting point of the compound. The thermogravimetry (TG) and differential scanning calorimetry (DSC) analyses were carried out in the range of temperature $30{ }^{\circ} \mathrm{C}$ to $1200{ }^{\circ} \mathrm{C}$ at a heating rate of 20 ${ }^{\circ} \mathrm{C} / \mathrm{min}$ in an $\mathrm{Al}_{2} \mathrm{O}_{3}$ crucible in a nitrogen atmosphere. The TG-DSC trace of B4ATCZ shown in Fig. 7 demonstrates that the grown crystal is thermally stable up to $235^{\circ} \mathrm{C}$ because no decomposition happens up to this temperature. It also affirms that

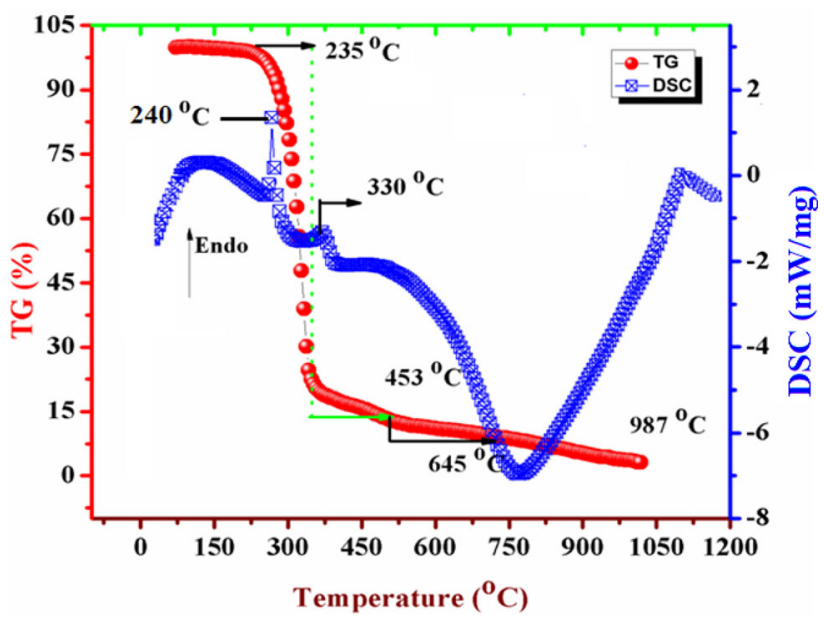

Fig. 7 TG-DSC thermal profile of B4ATCZ single crystal

there is no surface absorbed water molecules in the compound. In the TG curve, the first weight loss of $78.06 \%$ occurs between $235{ }^{\circ} \mathrm{C}$ and $453{ }^{\circ} \mathrm{C}$, which is due to the sublimation of the $\mathrm{Cl}, \mathrm{CO}_{2}$, the mixture of $\mathrm{C}_{2} \mathrm{H}_{4}$, and also the evolution of $\mathrm{NH}_{3}$. The second stage of weight loss of $12.36 \%$ in between the temperature of $453{ }^{\circ} \mathrm{C}$ to $645^{\circ} \mathrm{C}$ involves the evolution of $\mathrm{CO}$ and part of $\mathrm{ZnCl}_{2}$. Finally, the third stage of mass changes of $6.35 \%$ in the temperature range of $645{ }^{\circ} \mathrm{C}$ to $987^{\circ} \mathrm{C}$ leads to the liberation of residual carbons and zinc compounds in the B4ATCZ sample [39-41]. From the DSC trace, it is ascertained that the B4ATCZ compound evidences a constant heat-absorbing endothermic transition up to $240{ }^{\circ} \mathrm{C}$ implying the melting point (solid-liquid phase transitions) of the grown crystal. The second endothermic peak observed at $330{ }^{\circ} \mathrm{C}$ divulges the beginning of the decomposition of the B4ATCZ crystal. The sharpness of the peaks in DSC affirmed the high crystallinity and purity of the grown compound. The thermal stability of the grown B4ATCZ crystal $\left(235{ }^{\circ} \mathrm{C}\right)$ is higher temperature than the earlier reported thermal stability values $\left(187^{\circ} \mathrm{C}\right)$ [18]. Furthermore, the thermal stability of B4ATCZ was also compared with some of the organic and semi-organic nonlinear optical crystals and is given in Table 1 . The excellent thermal stability of the B4ATCZ due to the hydrogen bonding which is responsible for the close packing of molecules is increased thermal and mechanical stability [42]. Therefore, the bis (4-acetylanilinium) tetrachloridozincate could be suitable material for nonlinear optical and photonic device fabrication below the temperature range of $240{ }^{\circ} \mathrm{C}$. 
Table 1 Comparison of the B4ATCZ thermal stability with other nonlinear optical crystals

\begin{tabular}{lll}
\hline Compound & Thermal stability $\left({ }^{\circ} \mathrm{C}\right)$ & References \\
\hline 2-(4-Fluorobenzylidene) malononitrile & 119.81 & {$[2]$} \\
Anilinium D-tartrate & 132.5 & {$[6]$} \\
Bis-4-acetylanilinium tartrate & 143.39 & {$[8]$} \\
Dichlorobis(1-proline)zinc(II) & 230 & {$[14]$} \\
Guanidinium manganese sulfate hydrate & 73 & {$[15]$} \\
Dichlorobis(4-chloroaniline-kN)zinc & 135 & {$[17]$} \\
4-Methyl anilinium phenolsulfonate & 192 & {$[19]$} \\
L-Glutamic acid zinc chloride & 219.9 & {$[26]$} \\
Bis (4-acetylanilinium) tetrachloridozincate & 235 & Present work \\
& &
\end{tabular}

\subsection{Mechanical hardness studies}

The important mechanical parameters of materials such as microhardness number $\left(H_{\mathrm{v}}\right)$, yield strength $\left(\sigma_{\mathrm{y}}\right)$, elastic stiffness constant $\left(\mathrm{C}_{11}\right)$, fracture toughness $\left(K_{\mathrm{c}}\right)$, Brittle index $\left(B_{\mathrm{i}}\right)$, and plasticity were estimated by subjecting the crystal to Vickers microhardness test. Mechanical properties of the materials strongly depend on the molecular structure, the number of bonds per unit volume, and composition of crystalline solids and are also elucidated as the resistance against the motion of dislocations and deformation under applied stress [43]. Hence, the mechanical hardness of material plays an essential role in device processing. The mechanical stability of the crack-free well-polished surface of B4ATCZ crystal was intended by Vickers microhardness tester with a diamond pyramidal indentor coupled to an optical microscope. This measurement was employed on the surface of B4ATCZ crystal with different loads ranging from 25 to $100 \mathrm{~g}$ in ambient temperature with a constant indentation time of $10 \mathrm{~s}$. The Vicker's microhardness value $\left(H_{\mathrm{v}}\right)$ was correlated to the applied load $(P)$ and the diagonal length of indentation impression $(d)$ as follows:

$H_{\mathrm{v}}=1.8544 \frac{P}{d^{2}}\left(\mathrm{~kg} / \mathrm{mm}^{2}\right)$.

The variation of applied load $(P)$ with the hardness number $\left(\mathrm{H}_{\mathrm{v}}\right)$ is shown in Fig. 8a. It is concluded that $H_{\mathrm{v}}$ increases with an increase in load $P$ and this signifies the reverse indentation size effect (RISE) which is owing to the indentation cracking [27]. The association of applied load with average indentation is expressed by Meyer's law:

$P=K_{1} d^{n}$

$\log P=\log K_{1}+n \log d$, where ' $K_{1}$ ' is the standard hardness constant and ' $n$ ' is Meyer's index number or work hardening coefficient. Meyer's index number of B4ATCZ crystal is 2.26 calculated by the least square fitting (Fig. 8b) method. According to the Onitsch concept, the attained $(n=2.26)$ value suggests that the grown B4ATCZ crystal belongs to soft material categories $[28,44]$.

\subsubsection{Yield strength}

From Meyer's index number $(n)$ and microhardness value $\left(\mathrm{H}_{\mathrm{v}}\right)$, the yield strength $\left(\sigma_{\mathrm{y}}\right)$ of the crystal can be studied using the following relation [38]:

$\sigma_{\mathrm{y}}=\frac{3-n}{2.9}\left\{\frac{12.5(n-2)}{3-n}\right\}^{n-2} H_{\mathrm{v}}$.

A graph of load $(P)$-dependent yield strength $\sigma_{\mathrm{y}}$ is represented in Fig. 9a.

\subsubsection{Elastic stiffness constant}

Using Wooster's empirical relation, the elastic stiffness constant $\left(C_{11}\right)$ for the grown crystal can be expressed by the relation [38]:

$C_{11}=\left(H_{\mathrm{v}}\right)^{7 / 4}$.

The elastic stiffness provides an opinion of the nature and strength of bonding of atoms to their neighbors. The graph drawn between load $P$ and $C_{11}$ is illustrated in Fig. $9 \mathrm{~b}$ and it evinces that the elastic stiffness increases with the increase of applied load. The larger stiffness constant $\left(C_{11}\right)$ value confirmed that the binding forces between the ions are perfectly strong in the bis (4-acetylanilinium) tetrachloridozincate crystal. 

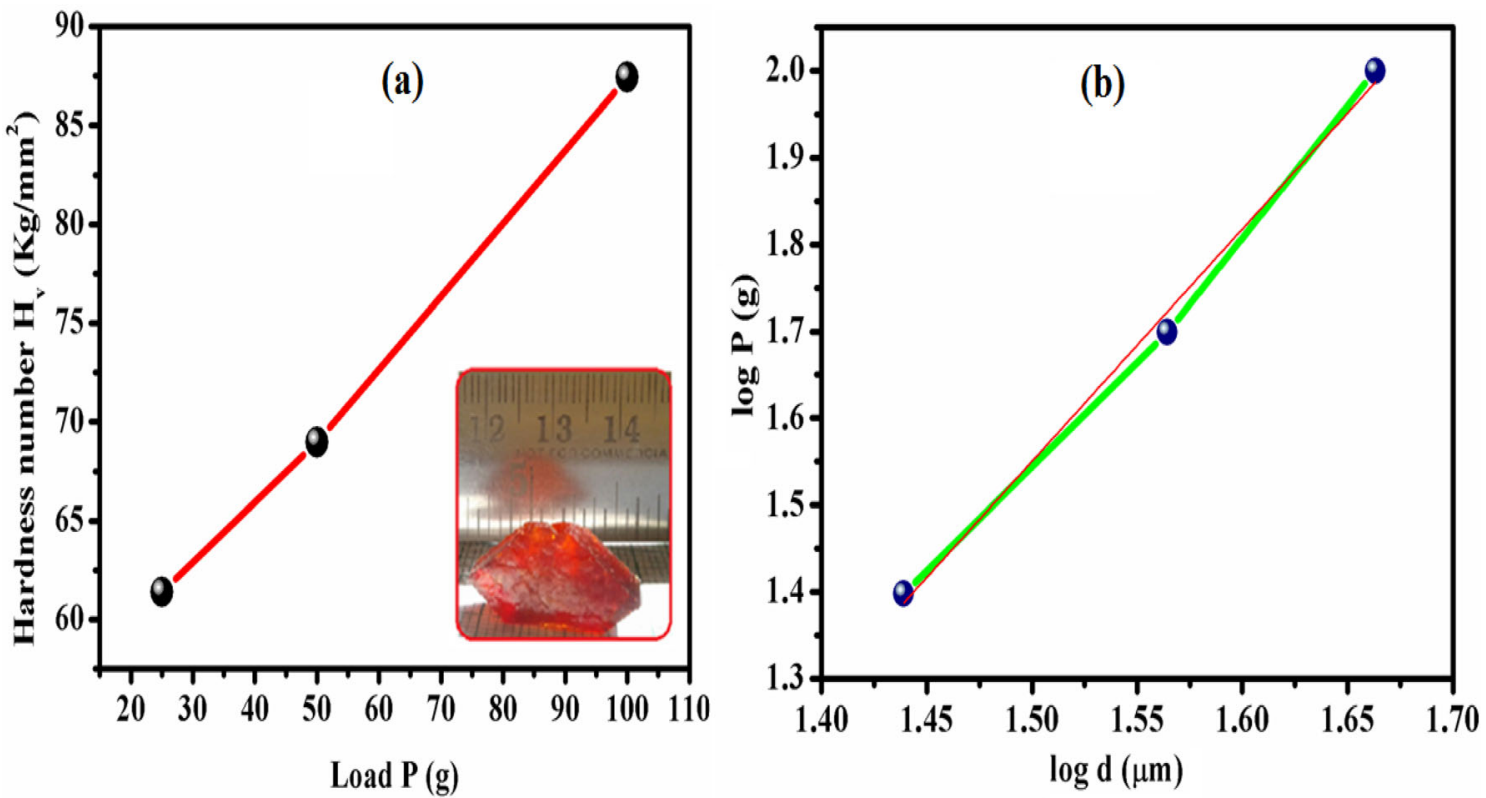

Fig. 8 a Variation of $\left(H_{\mathrm{v}}\right)$ versus applied load $(P)$, b Meyer's plot for B4ATCZ crystal

\subsubsection{Knoop hardness}

The Knoop hardness number $\left(H_{\mathrm{k}}\right)$ of each load was evaluated by the relation $[45,46]$ :

$H_{\mathrm{k}}=14.229 \frac{P}{d^{2}}\left(\mathrm{~kg} / \mathrm{mm}^{2}\right)$.

A plot is drawn between the variation of load $(\mathrm{P})$ and Knoop hardness number $\left(H_{\mathrm{k}}\right)$ is presented in Fig. 9c.

\subsubsection{Fracture toughness}

The fracture toughness $\left(K_{\mathrm{c}}\right)$ is the decisive mechanical parameter for the selection of material for practical device fabrications. The resistance to fracture testifies the toughness of the material and also it implies how much of fracture is induced under uniform loading. The fracture toughness for the median type of crack system is calculated by the following relation [47]:

$K_{\mathrm{c}}=\frac{P}{\left(\beta C^{3 / 2}\right)}$,

where ' $\beta$ ' is the indenter constant taken as 7 for the Vickers indenter and ' $C$ ' is the length of crack measured from the center of the indentation mark to the crack end.

\subsubsection{Brittleness index}

The brittleness provides detailed information about the fracture induced in a material, without any considerable deformation, and is a necessary property that affects the mechanical characteristics of a material. The brittle index $\left(B_{\mathrm{i}}\right)$ value is calculated by the expression [46]:

$B_{\mathrm{i}}=\frac{H_{\mathrm{v}}}{K_{\mathrm{c}}}$.

The evaluated mechanical parameters such as Vickers hardness $\left(H_{\mathrm{v}}\right)$ and Knoop hardness number $\left(H_{\mathrm{k}}\right)$, yield strength $\left(\sigma_{\mathrm{y}}\right)$, elastic stiffness constant $\left(C_{11}\right)$, fracture toughness $\left(K_{\mathrm{c}}\right)$, and brittle index $\left(B_{\mathrm{i}}\right)$ for various loads $(P)$ from 25 to $100 \mathrm{~g}$ for the bis (4acetylanilinium) tetrachloridozincate crystal are enumerated in Table 2.

\subsubsection{Hays-Kendall (HK) approach}

The Hays-Kendall (HK) approach gives observation of the indentation size effect (ISE) behavior of materials and also the load $(P)$ dependence of hardness can be analytically expressed by the following relation [48]:

$P=W+A_{1} d^{n}$,

where ' $W$ ' is the resistance pressure or the minimum applied load to initiate permanent plastic 

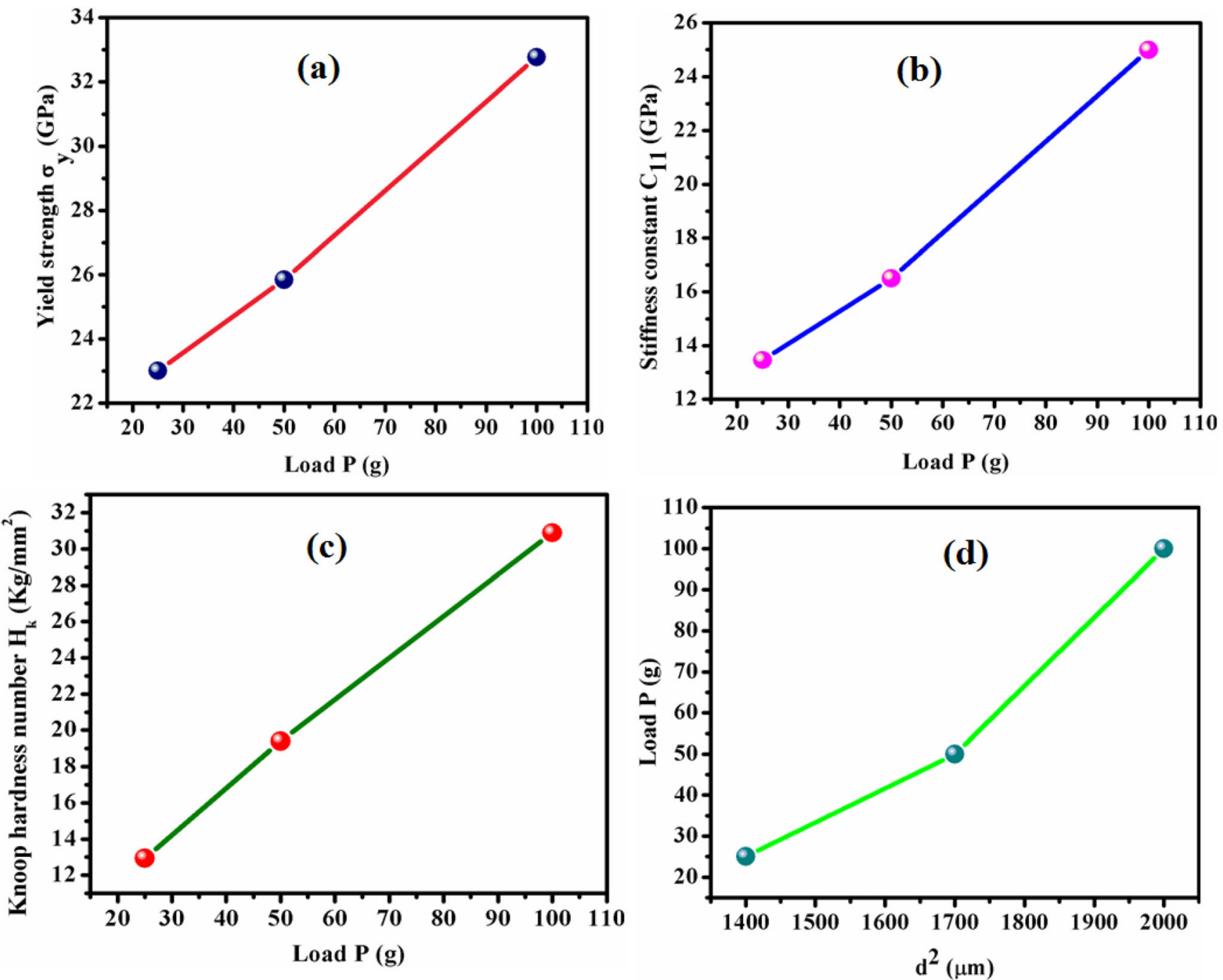

Fig. 9 a Variation of load $P$ vs. yield strength $\left(\sigma_{\mathrm{y}}\right)$, b load $P$ vs. stiffness constant $\left(C_{11}\right)$, $\mathbf{c}$ load $P$ vs. Knoop hardness $\left(H_{\mathrm{k}}\right), \mathbf{d}$ the plot of applied load $(P)$ vs. $d^{2}$ for the B4ATCZ crystal

Table 2 Calculated mechanical parameters of bis (4-acetylanilinium) tetrachloridozincate crystal

\begin{tabular}{llllllr}
\hline Load $P(\mathrm{~g})$ & $H_{\mathrm{v}}\left(\mathrm{kg} \mathrm{mm}^{-2}\right)$ & $H_{\mathrm{k}}\left(\mathrm{kg} \mathrm{mm}^{-2}\right)$ & $\sigma_{\mathrm{y}}(\mathrm{GPa})$ & $C_{11}(\mathrm{GPa})$ & $K_{\mathrm{c}} \times 10^{5}\left(\mathrm{~kg} \mathrm{~m} \mathrm{~m}^{-3 / 2}\right)$ & $B_{\mathrm{i}} \times 10^{5}$ \\
\hline 25 & 61.39 & 12.94 & 23.01 & 13.46 & 7.14 & 8.59 \\
50 & 68.97 & 19.40 & 25.85 & 16.50 & 14.28 \\
100 & 87.42 & 30.89 & 32.77 & 24.99 & 28.57 & 4.82 \\
\hline
\end{tabular}

deformation and ' $A_{1}$ ' indicates the load-independent constant with the exponent of $n=2.26$. The values of $(W)$ and $\left(A_{1}\right)$ were calculated by plotting the experimental data as the applied load $(P)$ and $d^{2}$ are shown in Fig. 9d and it is noticed that resistance pressure $(W)$ possesses a negative value revealing the strong reverse indentation size effect (RISE) behavior of the
B4ATCZ crystal [46]. The corrected load-independent hardness $\left(H_{\mathrm{HK}}\right)$ value of the grown crystal (Table 3 ) was determined to utilize the relation:

$H_{\mathrm{HK}}=1854.4 A_{1}$.

Therefore, the microhardness measurement of the B4ATCZ crystal confirmed that it obtains appreciable 
Table 3 Result of Hay's Kendall constant $W, A_{1}$, and $\underline{\mathrm{H}}_{\mathrm{HK}}$ for B4ATCZ crystal

\begin{tabular}{ll}
\hline HK constant & Results \\
\hline Resistance pressure $(\mathrm{W})$ & $-32.9268(\mathrm{~g})$ \\
Load-independent constant $\left(A_{1}\right)$ & $0.0725\left(\mathrm{~g} / \mu^{2}\right)$ \\
Corrected load-independent hardness $\left(H_{\mathrm{HK}}\right)$ & $134.444\left(\mathrm{~g} / \mu \mathrm{m}^{2}\right)$ \\
\hline
\end{tabular}

mechanical stability for various nonlinear optical device fabrications.

\subsection{Laser-induced damage threshold study}

Good optically transparent materials experience laser damage threshold (LDT) owing to the physical mechanisms like electron avalanche, photo-ionization by thermal absorption, photochemical dissociation, multiphoton absorption, and electrostrictive fracture $[49,50]$. The performance of nonlinear optical materials not only depends on the optical, thermal, and mechanical behavior but also predominantly relies on its surface quality for their capacity to withstand high-power intensities. Furthermore, the optical damage tolerance depends on external factors like irradiance, pulse duration, fluence, pulse repetition rate, and also experimental geometry. For this study, LDT measurement of B4ATCZ crystal implemented utilizing the Q-switched pulsed Nd: YAG laser of wavelength $1064 \mathrm{~nm}$ operating in $\mathrm{TEM}_{00}$ mode having a pulse width of $10 \mathrm{~ns}$ in frequency rate $10 \mathrm{~Hz}$. The surface laser damage threshold of the bis (4acetylanilinium) tetrachloridozincate has been calculated using the following expression:

Power density $\left(P_{\mathrm{d}}\right)=\frac{E}{\tau \pi r^{2}}\left(\mathrm{GW} / \mathrm{cm}^{2}\right)$,

where ' $E$ ' denotes the maximum input energy required to promote the damage $(\mathrm{mJ})$, ' $\tau$ ' is the pulse width (ns), and ' $r$ ' is the area of the circular spot $(\mathrm{mm})$. The obtained laser-induced damage pattern of B4ATCZ for the prominent (1 00 ) plane is shown in Fig. 10, tiny blobs surrounding the core of the damage, owing to thermal effects resulting in melting, flawing, decomposition, and solidification of the material. The laser damaged threshold value for the title crystal is $\left(19.78 \mathrm{GW} / \mathrm{cm}^{2}\right)$ which is very higher as compared to other well-known various nonlinear optical materials presented in Table 4 [49-54].

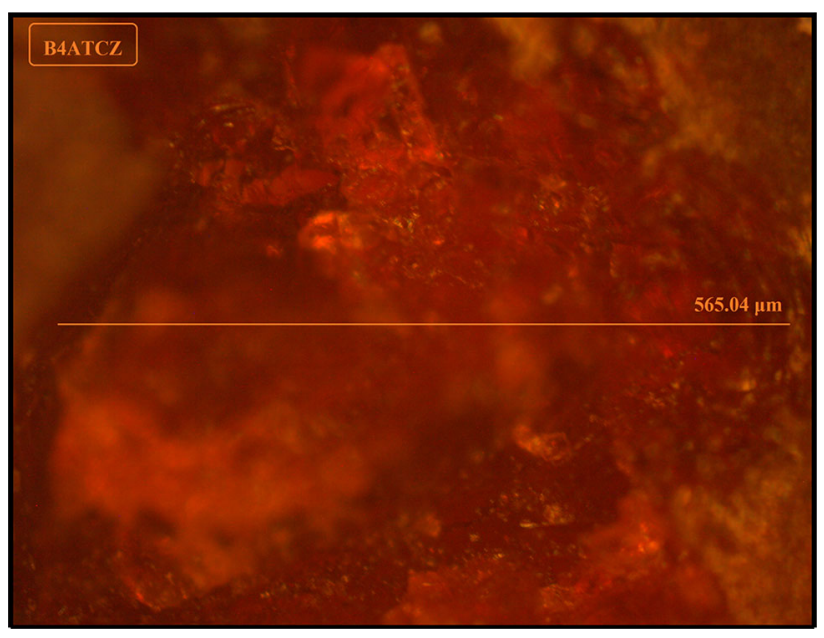

Fig. 10 A magnified damage surface photograph of the B4ATCZ crystal

Therefore, the eminent LDT value confirms that the bis (4-acetylanilinium) tetrachloridozincate crystal has a good resisting surface and also it can be a useful candidate for high-power laser appliances.

\subsection{Dielectric studies}

The dielectric characterization is one of the important electrical responses of the materials that are directly interconnected with the electro-optic properties of the crystals [55]. The analysis of dielectric gives crucial information about the structural property, defect behavior, and various polarization mechanisms of the materials. The microelectronics industry currently demands low dielectric constant materials continually for the application of interlayer dielectrics to decrease RC delay, lower power consumption, and to minimize cross talk between nearby interconnects $[56,57]$. The frequency-dependent dielectric constant $\left(\varepsilon^{\prime}\right)$ and dielectric loss $\left(\varepsilon^{\prime \prime}\right)$ of B4ATCZ single crystal were assessed from the measured capacitance using the given equations:

$\varepsilon^{\prime}=\frac{C_{\mathrm{p}} d}{A \varepsilon_{0}}$

$\varepsilon^{\prime \prime}=\varepsilon^{\prime} \tan \delta$,

where ' $C_{\mathrm{p}}$ ' is the capacitance across the sample $(\mu \mathrm{F})$, ' $d$ ' is the thickness of grown crystal $(\mathrm{mm})$, ' $A$ ' is the cross-sectional area of the sample $\left(\mathrm{mm}^{2}\right),{ }^{\prime} \varepsilon_{\mathrm{o}}$ ' is the free space permittivity $\left(8.854 \times 10^{-12} \mathrm{~F} \mathrm{~m}^{-1}\right)$, and 'tan $\delta^{\prime}$ is the dissipation factor. The dielectric constant and dielectric loss as a function of frequency at various 
Table 4 The laser-induced damage threshold value of B4ATCZ with reported NLO materials

\begin{tabular}{lcc}
\hline Compound & Laser-induced damage threshold value $\left(\mathrm{GW} / \mathrm{cm}^{2}\right)$ & References \\
\hline FBM & 2.14 & {$[2]$} \\
B4AAT & 15.78 & {$[8]$} \\
GuMnS & 1.157 & {$[15]$} \\
4AAPCl & 3.72 & {$[24]$} \\
PCNCN & 5.42 & {$[49]$} \\
BAP & 0.98 & {$[50]$} \\
FMP & 3.76 & {$[51]$} \\
LTT & 6.57 & {$[52]$} \\
2A5MPNB & 4.21 & {$[53]$} \\
QNP & 6.25 & {$[54]$} \\
B4ATCZ & 19.78 & Present work \\
\hline
\end{tabular}

temperatures for B4ATCZ crystal are illustrated in Fig. 11a and b, respectively. The dielectric plots of bis (4-acetylanilinium) tetrachloridozincate crystal

(a)

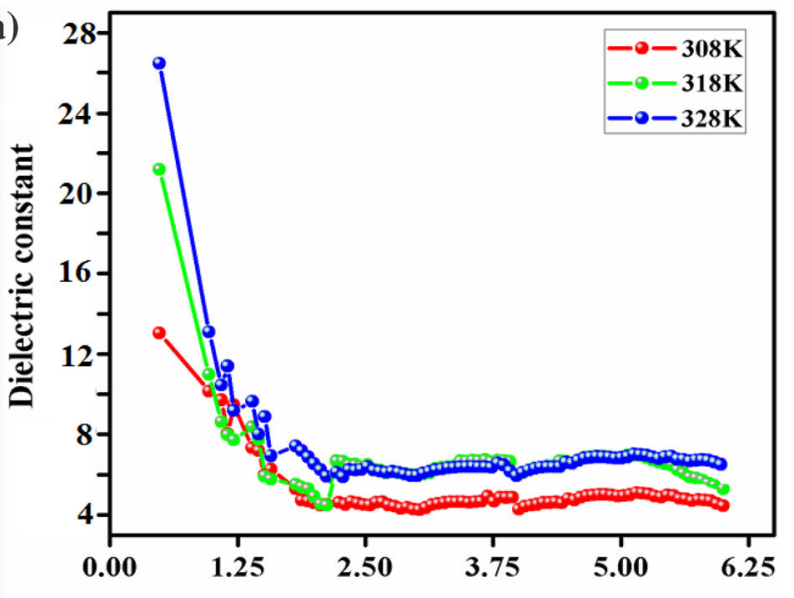

(b)

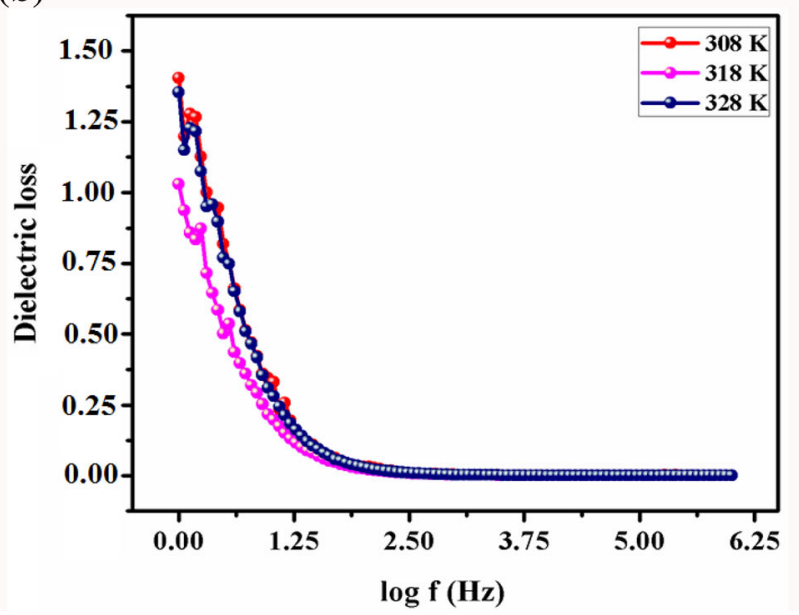

Fig. 11 a The plot of log frequency vs dielectric constant of B4ATCZ crystal, $\mathbf{b}$ the plot of log frequency vs dielectric loss of B4ATCZ crystal revealed that both the values of dielectric constant and dielectric loss are almost high at a lower frequency region and very low at a higher frequency region. Furthermore, the dielectric constant $\left(\varepsilon^{\prime}\right)$ and loss $\left(\varepsilon^{\prime \prime}\right)$ values are found to decrease with increasing frequency at all the related temperatures and this symbolizes the normal dielectric behavior of the B4ATCZ compound. The magnitude of $\varepsilon^{\prime}$ is a measure of the electrostatic binding strength between ions. The greater value of $\varepsilon^{\prime}$ at a lower frequency region is owing to the contributions of all the four polarization mechanisms (Miller's rule) such as interfacial, dipolar, ionic, and electronic polarization, whereas the very low value of $\varepsilon^{\prime}$ at a higher frequency region is the result of continuous loss of significance of the polarization. At higher frequency region, dipoles could not pursue the applied electric field; in this manner, the polarization decreases and also the dielectric constant value of the B4ATCZ is decreased. This is due to the thermally generated charge carriers and impurities of dipoles [57-59]. Also, the low value of $\varepsilon^{\prime \prime}$ at higher frequencies satisfies that the grown crystal has an enlarged optical quality with fewer defects. From the dielectric constant plot (Fig. 11a), clearly noticed that the $\varepsilon^{\prime}$ value of B4ATCZ crystal is 26.2 at $328 \mathrm{~K}$ which is in good agreement with previously reported bis (4-acetylanilinium) tetrachloridozincate compound $\left(\varepsilon^{\prime} \approx 25\right)[18]$ and is lower than that of some well-known anilinium derivative photonic NLO crystals, such as 4-methylanilinium-3carboxy-4-hydroxybenzenesulfonate crystal $\left(\varepsilon^{\prime} \approx 49\right)$ [60], and also significantly very lower than some semi-organic electro-optic materials like $\mathrm{KNbo}_{3}\left(\varepsilon^{\prime}\right.$ $\approx 154)$ [61] and $\mathrm{LiNbo}_{3}\left(\varepsilon^{\prime} \approx 85\right)$ [62]. Therefore, the lower dielectric constants values of B4ATCZ crystal 
could be a potential candidate for laser, electro-optic, photonic, and microelectronic device applications.

\subsection{Evaluation of solid-state parameters}

The electronic polarizability of the material is an important feature for the performance of the nonlinear optical effects. There are several theoretical approaches applicable for measuring the electronic polarizability of the materials such as optical bandgap, Lorentz-Lorenz equation, Penn analysis, and Clausius-Mossotti relation. In the higher frequency range $(1 \mathrm{MHz})$, the dielectric constant $\left(\varepsilon_{\infty}\right)$ of the B4ATCZ was calculated to be 26.2 at $55{ }^{\circ} \mathrm{C}$ and it is used to interpret the solid-state parameters of the crystals. The density of the title compound is determined by the following equation:

$\rho=\frac{M Z}{N_{\mathrm{A}} V}$,

where ' $M$ ' indicates the molecular weight (479.54 $\mathrm{g} / \mathrm{mol}$ ) of the B4ATCZ crystal, ' $\mathrm{Z}$ ' is the molecular unit cell $(Z=8)$, ' $N_{\mathrm{A}}$ ' denotes Avogadro's number $\left(6.023 \times 10^{23} \mathrm{~mol}^{-1}\right)$, and ' $\mathrm{V}$ ' is the volume of the unit cell $\left(4.14 \times 10^{-21} \mathrm{~cm}^{3}\right)$. The evaluated density of the B4ATCZ compound is $1.53 \mathrm{~g} / \mathrm{cm}^{3}$. The valence electron plasma energy $\left(\hbar \omega_{\mathrm{p}}\right)$ was estimated by the given equation [63]:

$\hbar \omega_{\mathrm{p}}=28.8\left(\frac{Z^{\prime} \rho}{M}\right)^{1 / 2}$.

The Penn gap and Fermi energy in terms of the plasma energy were calculated by the following relations [64]:

$E_{\mathrm{p}}=\frac{\hbar \omega_{p}}{\left(\varepsilon_{\infty}-1\right)^{1 / 2}}$

$E_{\mathrm{f}}=0.2948\left(\hbar \omega_{\mathrm{p}}\right)^{4 / 3}$.

Further, the electronic polarizability $(\alpha)$ of the B4ATCZ compound was determined using the following relation [65]:

$\hbar \alpha=\left[\frac{\left(\omega_{\mathrm{p}}\right)^{2} S_{\mathrm{o}}}{\left(\omega_{\mathrm{p}}\right)^{2} S_{\mathrm{o}}+3 E_{\mathrm{p}}^{2}}\right] \times \frac{M}{\rho} \times 0.396 \times 10^{-24} \mathrm{~cm}^{3}$,

where ' $S_{\mathrm{o}}$ ' is a constant for a specific material which is given by
$S_{\mathrm{o}}=1-\left[\frac{E_{\mathrm{p}}}{4 E_{\mathrm{f}}}\right]+\frac{1}{3}\left[\frac{E_{\mathrm{p}}}{4 E_{\mathrm{f}}}\right]^{2}$.

Using the Clausius-Mossotti relation, the value of electronic polarizability $(\alpha)$ was easily obtained by the following relation [66]:

$\alpha=\frac{3 M}{4 \pi N_{\mathrm{A}} \rho}\left[\frac{\varepsilon_{\infty}-1}{\varepsilon_{\infty}+2}\right] \mathrm{cm}^{3}$.

The relation between the electronic polarization $(\alpha)$ and linear refractive index $(\mu)$ is expressed by the following Lorentz-Lorenz equation [67]:

$\alpha=\frac{3 M}{4 \pi N_{A} \rho}\left[\frac{\mu^{2}-1}{\mu^{2}+2}\right] \mathrm{cm}^{3}$.

The electronic polarizability $(\alpha)$ was also calculated by using the optical bandgap value of the B4ATCZ crystal and it is given by [68]

$\alpha=\left[1-\frac{\sqrt{E_{\mathrm{g}}}}{4.06}\right] \times \frac{M}{\rho} \times 0.396 \times 10^{-24} \mathrm{~cm}^{3}$

All these calculated solid-state parameters for the grown bis (4-acetylanilinium) tetrachloridozincate crystal are presented in Table 5.

\subsection{Photoconductivity studies}

The photoconductive materials ought to be efficient for converting the low energy content of subpicosecond laser pulses to electric pulses of comparatively high amplitude. The photoconductivity of materials forms the basis of photoresistors, memories, sensors, and other devices [69]. In general, some of the physical processes such as carrier generation, carrier lifetime, carrier density, transport, trapping, and recombination processes are more responsible for the generation of photoconductivity in a crystal. It confirms the gain or loss of charge carrier of the materials in the presence of radiation for the applied electric potential [70]. For this measurement, a wellpolished transparent B4ATCZ crystal $3 \times 3 \times 2 \mathrm{~mm}^{3}$ in size was coated with silver paste on both surfaces to make good ohmic contact between the electrodes and connected in series to a DC power supply with a picoammeter. The field dependence dark and photocurrent responses of the grown B4ATCZ crystal were measured at room temperature and are illustrated in Fig. 12. From the plot, it is inferred that the dark and photocurrent are exactly linear with the 
Table 5 Estimated solid-state parameters of the grown B4ATCZ compound

\begin{tabular}{ll}
\hline Solid-state parameters & Estimated values \\
\hline Plasma energy $\left(\hbar \omega_{\mathrm{p}}\right)$ & $25.4109(\mathrm{eV})$ \\
Penn gap energy $\left(E_{\mathrm{p}}\right)$ & $5.06197(\mathrm{eV})$ \\
Fermi energy $\left(E_{\mathrm{F}}\right)$ & $22.02356(\mathrm{eV})$ \\
Specific material constant $\left(S_{\mathrm{o}}\right)$ & 0.943640 \\
Electronic polarizability using Penn analysis $(\alpha)$ & $11.0212 \times 10^{-23}\left(\mathrm{~cm}^{3}\right)$ \\
Electronic polarizability using Clausius Mossotti $(\alpha)$ & $11.1071 \times 10^{-23}\left(\mathrm{~cm}^{3}\right)$ \\
Electronic polarization using linear refractive index $(\alpha)$ & $4.5959 \times 10^{-23}\left(\mathrm{~cm}^{3}\right)$ \\
Electronic polarization using optical bandgap value $(\alpha)$ & $6.45235 \times 10^{-23}\left(\mathrm{~cm}^{3}\right)$ \\
\hline
\end{tabular}

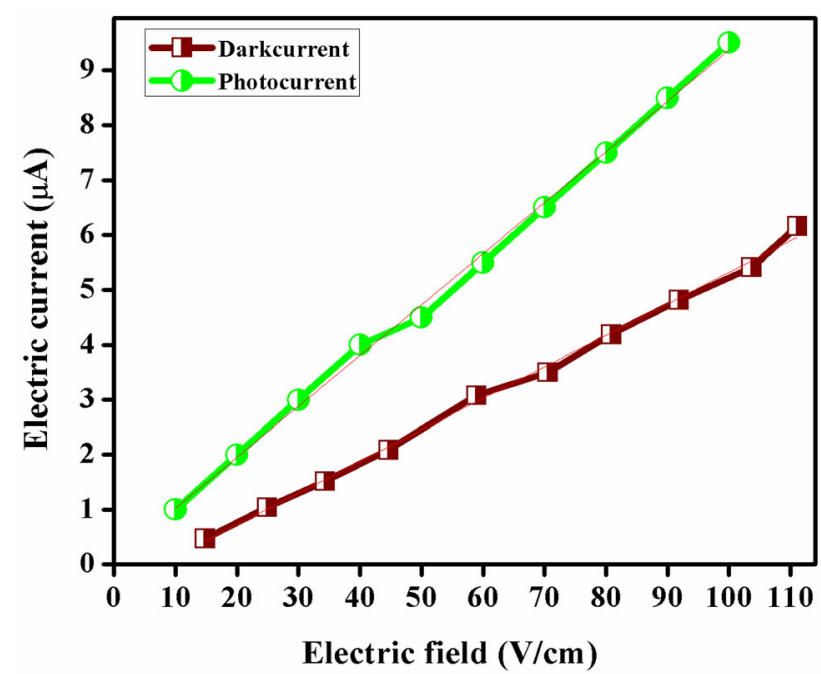

Fig. 12 Positive photoconductivity response of B4ATCZ single crystal

applied input voltage. The photocurrent was higher than that of the dark current which evidently shows the positive photoconductivity of the grown B4ATCZ crystal. This positive photoconductivity of crystal exists due to the production of mobile charge carriers induced by the absorption of the photons, whereas the larger value of photocurrent is owing to a flaw of traps and the population of an intrinsic center produced by direct excitation of charge carriers in the crystal [71, 72]. Furthermore, the B4ATCZ possesses a wide bandgap for photon absorption and it could be utilized for the soliton wave communication devices. Similar results were found in the examination of promising nonlinear optical crystals like strontium niobate, $\mathrm{NaLi}$, and NPNa [73].

\subsection{Photoluminescence and lifetime measurement}

The photoluminescence (PL) is one of the crucial nondestructive spectroscopic techniques to investigate the optical and electronic properties of solids. The phenomenon of photoluminescence is the spontaneous emission of light induced by photoexcitation. During the process, the loss of emission of photons is due to the internal conversion, intersystem crossing, and vibrational relaxation. The photolum inescence (PL) could be expected from the aromatic molecules which contain $\pi$-bonds of $\mathrm{sp}^{2}$ hybrid orbitals (multiple conjugated bonds) possessing a high degree of resonance stability $[74,75]$. The emission spectrum of the grown B4ATCZ was recorded in the range 300 to $650 \mathrm{~nm}$ at room temperature with an excitation wavelength of $300 \mathrm{~nm}$ as depicted in Fig. 13. The intense broad two eminent fluorescence emission peaks observed at $385 \mathrm{~nm}$ and $432 \mathrm{~nm}$, reveals that the ultraviolet and blue emission of the B4ATCZ

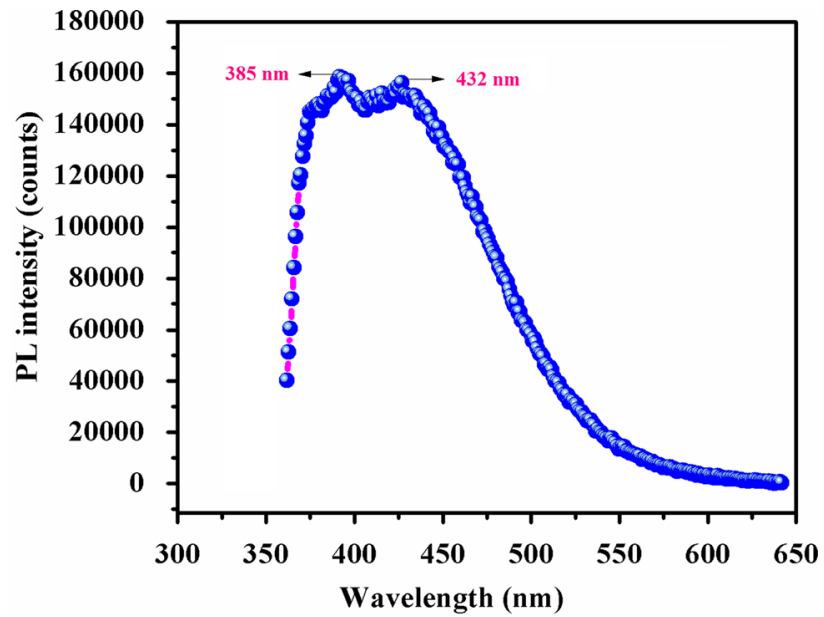

Fig. 13 The fluorescence emission spectrum of the grown B4ATCZ crystal 
crystal. The asymmetric and broadening emission of B4ATCZ is caused by the existence of several electronic transitions occurring in different energy levels within the bandgap [76]. The resultant fluorescence emission peaks represent the excellent optical quality with the fewer defects in the crystal and the luminescent nature of B4ATCZ hinter its applications towards UV fluorescence detection, UV filter, and optoelectronic devices [75]. The PL lifetime is a measure of the meantime of the molecule spent in the excited state before returning to the ground state by emitting a photon. The existence of a prompt and delayed component of fluorescence materials leads to neutron-gamma discrimination. The typical feature of this organic scintillator as a detector application is to estimate various lifetimes (prompt- $\left(\tau_{1}\right)$, delay1- $\left(\tau_{2}\right)$, and delay2- $\left.\left(\tau_{3}\right)\right)$ at the identical emission wavelength of $300 \mathrm{~nm}$. The profile lifetime of excited molecules determined for the B4ATCZ crystal by the TimeCorrelated Single-Photon Counting (TCSPC) method shown in Fig. 14a has three exponential decay time [34]. The three exponential decay components are fitted by the following relation:

$F(t)=A_{1} \mathrm{e}^{-t / \tau_{1}}+A_{2} \mathrm{e}^{-t / \tau_{2}}+A_{3} \mathrm{e}^{-t / \tau_{3}}$,

where $A_{1}, A_{2}$, and $A_{3}$ are amplitudes, and $\tau_{1}, \tau_{2}$, and $\tau_{3}$ indicate lifetimes of prompt and delayed emissions. The residual fit of the lifetime measurement for B4ATCZ crystal given in Fig. 14b signifies the most excellent fitting done to the actual decay curve. The

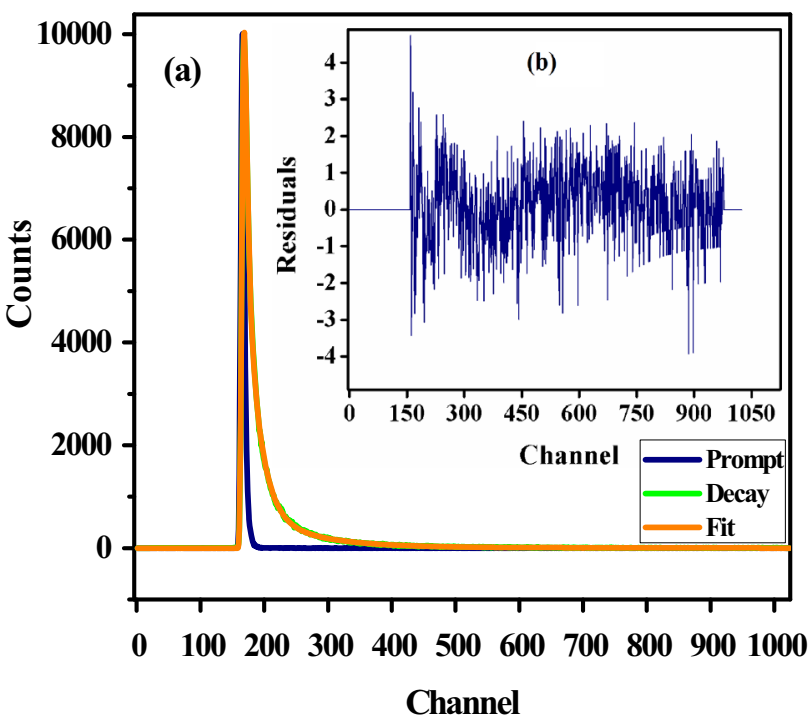

Fig. 14 a Fluorescence lifetime measurement, b residual fit (inset) of B4ATCZ crystal perfectness of the curve fit was arrested by the examination of the residuals and also from the evaluated value of the reduced nonzero second-order molecular polarizability $\chi^{(2)}$ ratio. The fast scintillation decay time in nonlinear optical molecular crystals lies between 2 and $30 \mathrm{~ns}$ [38]. The present lifetime analysis declares that the B4ATCZ crystal possesses the shortest decay components of lifetime and amplitude, which is detailed in Table 6. Hence, the active PL emission and its lifetime results confirm B4ATCZ is an excellent and appreciable candidate for new violet and blue LED device fabrications.

\subsubsection{HOMO-LUMO analysis}

In quantum chemistry, the study of the frontier molecular orbitals (FMOs) plays an essential role in exploring the optical and electrical properties and chemical reactivity of the molecule. The FMO examination of wave function attests that the electron absorption corresponds to the transition from the highest occupied molecular orbital (HOMO) to the lowest unoccupied molecular orbital (LUMO). A molecule with a small energy gap is more polarizable and is mainly correlated with low kinetic stability and high chemical reactivity [77]. The HOMOLUMO energy gap for the B4ATCZ is shown in Fig. 15. It is clear from the figure that HOMO orbitals are mainly distributed over the tetrachloridozincate anion $\left[\mathrm{ZnCl}_{4}{ }^{2-}\right]$ and LUMO orbitals are extended towards the bis (4-acetylanilinium) cation $\left[\left(\mathrm{C}_{8} \mathrm{H}_{10} \mathrm{NO}\right)^{+}\right]$. This explains the $\mathrm{N}-\mathrm{H} \cdots \mathrm{Cl}$ and $\mathrm{N}-$ $\mathrm{H} \cdots \mathrm{O}$ intermolecular charge transfer interaction occurred from tetrachloridozincate to bis (4-acetylanilinium) moiety through the strong hydrogen bond interaction and is a desirable behavior to obtain a large nonlinear optical response [41]. The calculated energy values of the HOMO and LUMO are -4.10 $\mathrm{eV}$ and $-0.28 \mathrm{eV}$, respectively. The FMO energy separation value of the B4ATCZ compound is $E_{\mathrm{g}}=$ $3.82 \mathrm{eV}$, which is in good agreement with the bandgap $\left(E_{\mathrm{g}}=3.8 \mathrm{eV}\right)$ obtained from UV spectral studies. Furthermore, the most important quantum chemical global reactivity descriptors such as ionization potential $(I)$, electron affinity $(A)$, electronegativity $(\chi)$, chemical potential $(\mu)$, chemical hardness $(\eta)$, chemical softness $(S)$, and electrophilicity index $(\omega)$ were calculated theoretically by using the value of FMO energy gap and the results are given in Table 7 . 
Table 6 Fluorescence lifetime studies of bis (4-

\begin{tabular}{|c|c|c|c|c|c|c|c|c|}
\hline \multirow[t]{2}{*}{ Crystal } & \multirow[t]{2}{*}{ Analysis } & \multicolumn{3}{|c|}{ Lifetime (ns) } & \multicolumn{3}{|c|}{ Amplitude } & \multirow[t]{2}{*}{$\chi^{(2)}$} \\
\hline & & $\tau_{1}$ & $\tau_{2}$ & $\tau_{3}$ & $A_{1}$ & $A_{2}$ & $A_{3}$ & \\
\hline B4ATCZ & Three exponential & 4.363 & 1.372 & 8.911 & 4.57 & 22.85 & 65.18 & 1.232 \\
\hline
\end{tabular}

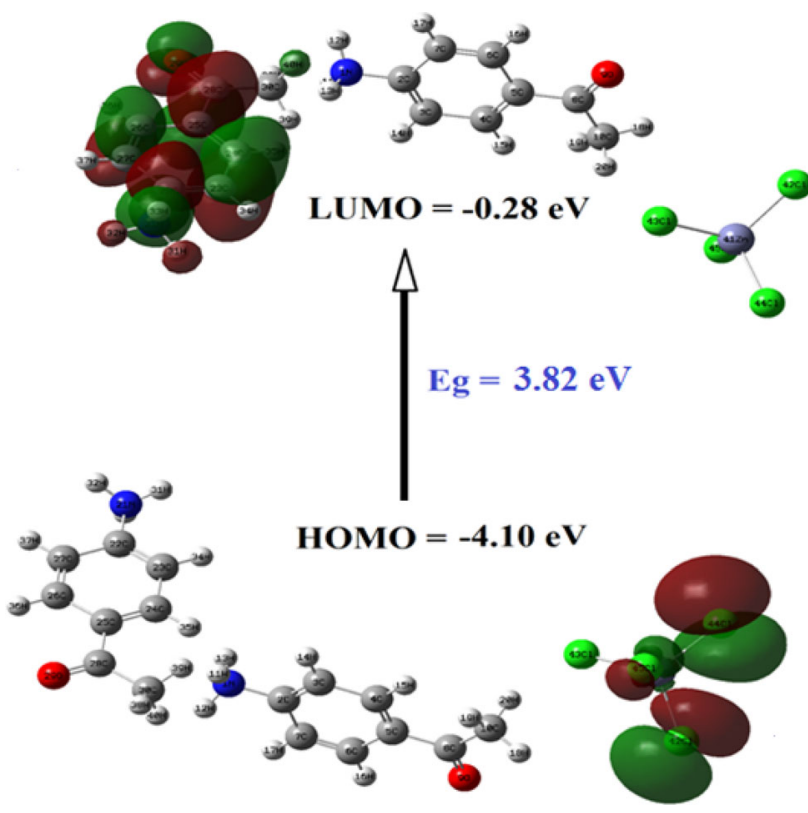

Fig. 15 The HOMO-LUMO 3D plot of B4ATCZ at B3LYP-6$311++\mathrm{G}(\mathrm{d}, \mathrm{p})$ level

Table 7 Calculated quantum chemical parameters of the B4ATCZ compounds

\begin{tabular}{lc}
\hline Quantum parameters $(\mathrm{eV})$ & B4ATCZ $(\mathrm{eV})$ \\
\hline HOMO & -4.10 \\
LUMO & -0.28 \\
$E_{\mathrm{g}}$ & 3.82 \\
$I=-$ HOMO & 4.10 \\
$A=-\mathrm{LUMO}$ & 0.28 \\
$\chi=(I+A) / 2$ & 2.19 \\
$\mu=-(I+A) / 2$ & 2.19 \\
$\eta=(I-A) / 2$ & 1.91 \\
$S=1 / 2 \eta$ & 0.261 \\
$\omega=-\chi^{2} / 2 \eta$ & 1.255 \\
\hline
\end{tabular}

\subsubsection{Molecular electrostatic potential surface}

The iso-surfaces of the 3D molecular electrostatic potential (MEP) plot provide charge distribution of molecules and also it contributes to the interaction between the molecular structure with its physicochemical characteristics like partial charges, dipole moment, chemical reactivity, and electronegativity $[78,79]$. Due to this desire, the MEP map of B4ATCZ is generated at the B3LYP/6-311++G $(d, p)$ level and is depicted in Fig. 16. The molecule with a blue color site indicates the positive regions of most repulsive electrostatic potential, while the red site denotes the negative regions of maximum attractive electrostatic potential and also the green part represents the region of zero potential. The different color code of the 3D-MEP plot (Fig. 16) is in the range between $-0.240 \mathrm{e}^{0}$ a.u and $+0.240 \mathrm{e}^{0}$ a.u for B4ATCZ compound. From the MEP plot, the strong attractive potentials are found over the electronegative chlorine and zinc atoms due to the immense conjugative and hyper conjugative resonance charge delocalization of $\pi$-electrons [80]. However, the repulsive electrostatic potential is spread over the protonated bis (4-acetylanilinium) moieties due to the influence of the oxygen atoms.

\subsubsection{Third-order nonlinear optical studies}

In the past ten decades, the third-order nonlinear optical materials from the metal-organic hybrid crystals have received a great deal of attention due to their potential applications in optical information storage, all-optical switching, optical limiters, optical logic gates, laser radiation protection, etc. [81, 82].

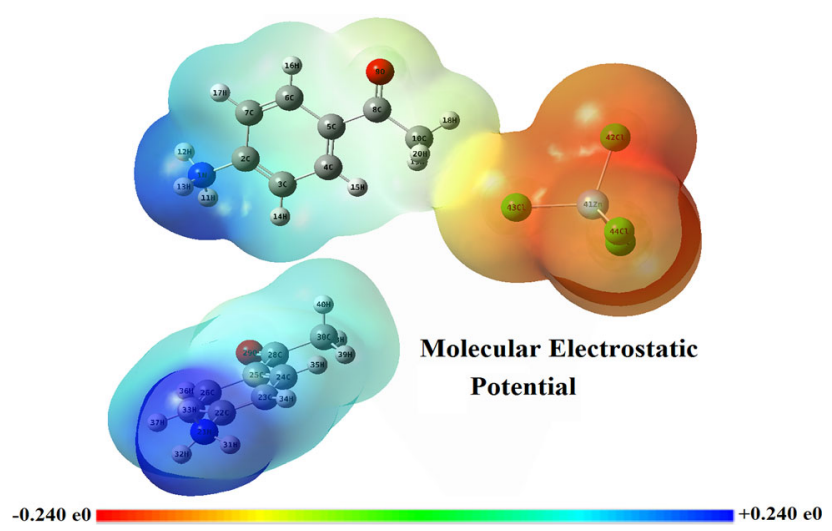

Fig. 16 The molecular electrostatic potential surface of B4ATCZ compound 
The Z-scan technique is the more convenient approach to find the intensity-dependent nonlinear refractive index $\left(n_{2}\right)$, nonlinear absorption coefficient $(\beta)$, and third-order nonlinear optical susceptibility $\left(\chi^{(3)}\right)$ for thin films, solids, and liquid samples. From the Z-scan technique, third-order nonlinear optical parameters of the materials were investigated by the open and close aperture mode Z-scan data. The open aperture of a Z-scan trace for the grown B4ATCZ crystal recorded (Fig. 17) divulges that the transmittance forms a valley at the focus known as reverse saturable absorption behavior of the material. Due to this reverse saturable absorption, the B4ATCZ compound is extensively used in laser-assisted device applications such as photonics, optical limiting, laser stabilization, and biomedical applications [83, 84]. In the closed aperture curve Fig. 18, the pre-focal transmittance minimum followed by a post-focal transmittance maximum exhibits the positive nonlinearity and self-focusing effects, and it is due to reduced transmittance and far-field divergence through the far-field aperture. This self-focusing behavior is responsible for the optical modulators, optical switching, and optical limiting in nonlinear optical materials $[85,86]$. The difference in the highest peak to the lowest valley transmission $\left(\Delta T_{\mathrm{p}-\mathrm{v}}\right)$ calculated in terms of the on-axis nonlinear phase shift at the focus $\left(\left|\Delta \Phi_{0}\right|\right)$ is expressed as

$\Delta T_{\mathrm{p}-\mathrm{v}}=0.406(1-S)^{0.25}\left|\Delta \Phi_{0}\right|$

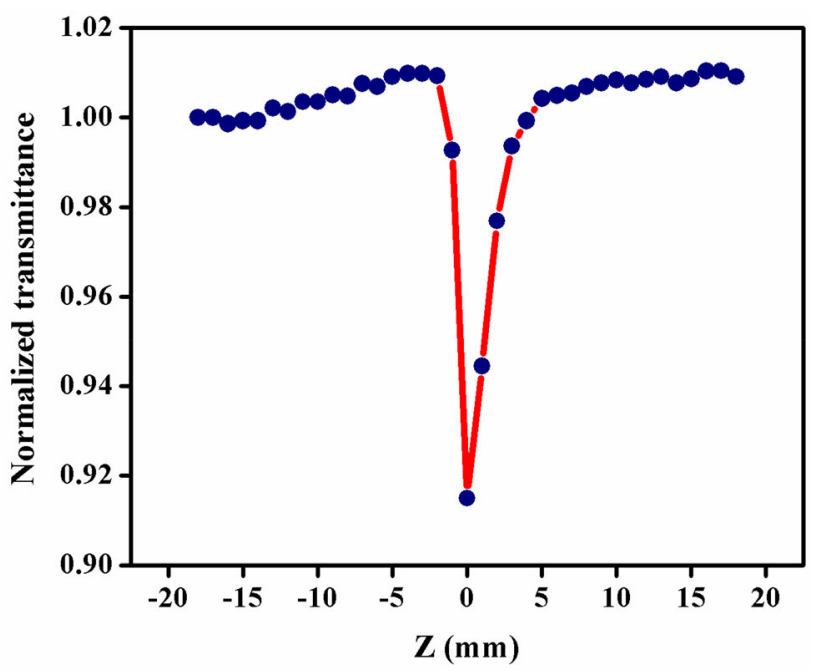

Fig. 17 Reverse saturable absorption in the open aperture Z-scan of B4ATCZ

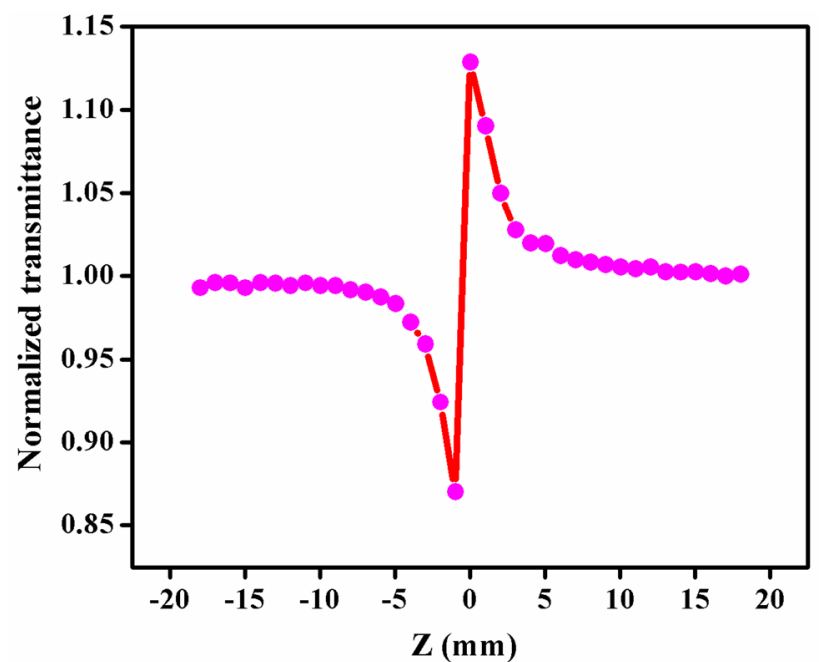

Fig. 18 Self-focusing behavior of B4ATCZ in closed aperture Z-scan curve

$S=1-\exp \left(\frac{-2 r_{\mathrm{a}}^{2}}{\omega_{\mathrm{a}}^{2}}\right)$,

where ' $S$ ' is the linear transmittance aperture, ' $r_{a}$ ' is the radius of the aperture, and ' $\omega_{\mathrm{a}}$ ' is the beam radius at the aperture. The nonlinear phase shift associated with refractive index ' $n_{2}$ ' of the materials was related by

$n_{2}=\frac{\Delta \phi_{0}}{K I_{0} L_{\mathrm{eff}}} \quad$ and

$L_{\mathrm{eff}}=\frac{[1-\exp (-\alpha L)]}{\alpha}$,

where ' $K$ ' indicates the wavenumber, ' $I_{0}$ ' is the intensity of the laser power at the focus $(Z=0)$, ' $L_{\text {eff }}$ ' is the effective propagation length of the sample with the crystal thickness ' $L$ ', and ' $\alpha$ ' is the linear absorption coefficient. From the open aperture Z-scan graph, the third-order nonlinear absorption coefficient $(\beta)$ was evaluated as

$\beta=\frac{2 \sqrt{2} \Delta T}{I_{0} L_{\mathrm{eff}}}$.

The real and imaginary parts of the $\chi^{(3)}$ have been deduced from the experimental results of ' $n_{2}$ ' and ' $\beta$ ' by the relations:

$\operatorname{Re} \chi^{(3)}(\mathrm{esu})=10^{-4} \frac{\varepsilon_{0} c^{2} n_{0}^{2} n_{2}}{\pi}\left(\frac{\mathrm{cm}^{2}}{\mathrm{~W}}\right)$ 
Table 8 Calculated thirdorder nonlinear optical parameters of the B4ATCZ crystal

\begin{tabular}{ll}
\hline Nonlinear refractive index $\left(n_{2}\right)$ & $4.72 \times 10^{-10} \mathrm{~cm}^{2} / \mathrm{W}$ \\
Nonlinear absorption coefficient $(\beta)$ & $2.862 \times 10^{-5} \mathrm{~cm} / \mathrm{W}$ \\
Linear refractive index of B4AAT $(\mu)$ & 1.662 \\
Real part of the third-order susceptibility $\left(\operatorname{Re} \chi^{3}\right)$ & $3.68 \times 10^{-8} \mathrm{esu}$ \\
Imaginary part of the third-order susceptibility $\left(\operatorname{Im} \chi^{3}\right)$ & $2.70 \times 10^{-8} \mathrm{esu}$ \\
Second-order molecular hyperpolarizability $(\gamma)$ & $2.043 \times 10^{-30} \mathrm{esu}$ \\
Third-order nonlinear optical susceptibility $\left(\chi^{3}\right)$ & $4.57 \times 10^{-8} \mathrm{esu}$ \\
\hline
\end{tabular}

Table 9 Comparison of $\left(\chi^{3}\right)$ values of B4ATCZ with other nonlinear optical compounds

\begin{tabular}{lll}
\hline Compound & Third-order nonlinear optical susceptibility $\left(\chi^{3}\right)$ & References \\
\hline 4AAPCl & $4.060 \times 10^{-8} \mathrm{esu}$ & {$[24]$} \\
LTT & $7.1368 \times 10^{-10} \mathrm{esu}$ & {$[52]$} \\
TP4N & $4.334 \times 10^{-8} \mathrm{esu}$ & {$[68]$} \\
8HQ2C5N & $3.51 \times 10^{-10} \mathrm{esu}$ & {$[88]$} \\
QN & $4.0751 \times 10^{-12} \mathrm{esu}$ & {$[89]$} \\
B4ATCZ & $4.57 \times 10^{-8} \mathrm{esu}$ & Present work \\
\hline
\end{tabular}

$\operatorname{Im} \chi^{(3)}(\mathrm{esu})=10^{-2} \frac{\varepsilon_{0} c^{2} n_{0}^{2} \lambda \beta}{4 \pi^{2}}\left(\frac{\mathrm{cm}^{2}}{\mathrm{~W}}\right)$

The magnitude of third-order NLO susceptibility $\left(\chi^{(3)}\right)$ was assessed using the relation:

$\left|\chi^{(3)}\right|=\left[\operatorname{Re}\left(\chi^{(3)}\right)^{2}+\operatorname{Im}\left(\chi^{(3)}\right)^{2}\right]^{\frac{1}{2}}$.

Furthermore, the second-order molecular hyperpolarizability is associated with the third-order bulk susceptibility.

$\gamma_{\mathrm{h}}=\frac{\chi^{(3)}}{L^{4} N}$ and

$L=\frac{\left(\mu^{2}+2\right)}{3}$,

where ' $N$ ' is the number density of molecules, ' $L$ ' is the local field correction factor of Lorentz approximation, and ' $\mu$ ' is the linear refractive index of the B4ATCZ crystal. The results of the Z-scan parameters of the crystal are enumerated in Table 8 and also the calculated $\left(\chi^{(3)}\right)$ of B4ATCZ crystal is compared with some of the previously reported nonlinear optical compounds in Table $9[87,88]$. The obtained results of the comparison signify that the B4ATCZ crystal possesses an excellent third-order nonlinear optical response. Therefore, the third harmonic generation study proves that the B4ATCZ compound could be ideally suitable for applications such as sensitive optical detectors and optical switching applications [89-91].

\section{Conclusion}

The efficient metal-organic single-crystal bis (4acetylanilinium) tetrachloridozincate of dimension $20 \times 12 \times 7 \mathrm{~mm}^{3}$ was successfully grown by the slow solvent evaporation method. The single-crystal XRD results confirm that the grown B4ATCZ crystal belongs to the orthorhombic system. The UV-Visible transmission spectrum demonstrates that the B4ATCZ crystal has 59\% transparency beyond the cut-off wavelength $326 \mathrm{~nm}$ covering the entire ultraviolet-visible region. Moreover, reflectance $(R)$, extinction coefficient $(K)$, absorption coefficient $(\alpha)$, refractive index $(\mu)$, optical conductivity $\left(\sigma_{\text {opt }}\right)$, and electric susceptibility $\left(\chi_{c}\right)$ were calculated to examine the optical properties of bis (4-acetylanilinium) tetrachloridozincate crystal. Thermal studies infer that the B4ATCZ compound was stable up to $235^{\circ} \mathrm{C}$. Microhardness studies reveal the mechanically soft nature of the crystal which exhibited the reverse indentation size effect. The LDT value of the B4ATCZ compound was endowed to be $19.78 \mathrm{GW} / \mathrm{cm}^{2}$ on testing with $1064 \mathrm{~nm} \mathrm{Nd:} \mathrm{YAG} \mathrm{laser} \mathrm{radiation.} \mathrm{The}$ low dielectric properties of the crystal were measured at ambient temperature suggesting the advantage of this material towards microelectronic device applications. The positive photoconductive response of B4ATCZ was supported by a linear increase of photocurrent on illumination. The luminescence study and the time-resolved decay calculation were also carried out for the B4ATCZ compound. The HOMOLUMO energies and the electrostatic potential surface 
of the grown B4ATCZ crystal explain their electronic transitional properties, relative polarity, and chemical reactivity. Z-scan studies with $\mathrm{CW}$ excitation demonstrate that the grown crystal exhibits reverse saturable absorption and self-focusing effect. These impeccable behaviors of B4ATCZ crystal make it a suitable material for optical limiting, switching, frequency conversion, photonic soliton wave propagation, and optoelectronic device fabrications.

Open Access This article is licensed under a Creative Commons Attribution 4.0 International License, which permits use, sharing, adaptation, distribution and reproduction in any medium or format, as long as you give appropriate credit to the original author(s) and the source, provide a link to the Creative Commons licence, and indicate if changes were made. The images or other third party material in this article are included in the article's Creative Commons licence, unless indicated otherwise in a credit line to the material. If material is not included in the article's Creative Commons licence and your intended use is not permitted by statutory regulation or exceeds the permitted use, you will need to obtain permission directly from the copyright holder. To view a copy of this licence, visit http://creativecommons.org/licen ses/by/4.0/.

\section{References}

1. M. Shkir, S. Muhammad, S. AlFaify, A.R. Chaudhry, A.G. Al-Sehemi, Shedding light on molecular structure, spectroscopic, nonlinear optical and dielectric properties of bis(thiourea) silver (I) nitrate single crystal: a dual approach. Arab. J. Chem. 12, 4612-4626 (2016). https://doi.org/10.10 16/j.arabjc.2016.06.016

2. A. Priyadharshini, S. Kalainathan, Bulk crystal growth and their effective third order nonlinear optical properties of 2-(4fluorobenzylidene) malononitrile (FBM) single crystal. Opt. Mater. 78, 35-43 (2018). https://doi.org/10.1016/j.optmat.20 18.02.017

3. S. Nandhini, K. Sudhakar, S. Muniyappan, P. Murugakoothan, Systematic discussions on structural, optical, mechanical, electrical and its application to NLO devices of a novel semi-organic single crystal: Guanidinium tetrafluoroborate (GFB). Optics Laser. Technol. 105, 249-256 (2018). h ttps://doi.org/10.1016/j.optlastec.2018.03.006

4. B. Uma, K. SakthiMurugesan, S. Krishnan, R. Jayavel, B. MiltonBoaz, Growth, optical, thermal and dielectric studies of a highly polarisable semiorganic NLO crystal: Bis D-phenyl glycinium sulphate monohydrate. Mater. Chem. Phys. 142, 659-666 (2013). https://doi.org/10.1016/j.matchemphys.201 3.08 .018

5. A. Priyadharshini, S. Kalainathan, Bulk crystal growth, spectral, optical, thermal, electrical and third-order NLO properties of benzylidene malononitrile derivative single crystal: a promising material for nonlinear optical device applications. J. Mater Sci. Mater Electron. 29, 2698-2708 (2017). https://doi.org/10.1007/s10854-017-8196-4

6. V. Subhashini, S. Ponnusamy, C. Muthamizhchelvan, Growth and characterization of novel organic optical crystal: Anilinium D-tartrate (ADT). Spectrochim. Acta Part A 87, 265-272 (2012). https://doi.org/10.1016/j.saa.2011.11.050

7. A. Jellibi, I. Chaabane, K. Guidara, Spectroscopic ellipsometry and UV-Vis studies at Room temperature of the novel organic-inorganic hybrid of salt Bis (4-acetylanilinium) tetrachlorocadmiate. Phys. E 79, 167-172 (2016). https://doi. org/10.1016/j.physe.2015.12.022

8. A. Abkari, I. Chaabane, K. Guidara, Synthesis, crystal structure, Spectroscopic characterization and optical properties of bis(4- acetylanilinium) tetrachlorocobalt (II). Phys. E 86, 210-217 (2017). https://doi.org/10.1016/j.physe.2016.06. 013

9. M.Amine Fersi, I. Chaabane, M. Gargouri, A. Bulou, A theoretical study on the molecular structure of new organicinorganic bis (4-acetylanilinium) tetrachloridozincate compound, Indian. J. Phys. 90 (2015) 381-389. DOI: https://doi. org/10.1007/s12648-015-0784-7.

10. P. Novák, K. Müller, K.S.V. Santhanam, O. Haas, Electrochemically active polymers for rechargeable batteries. Chem. Rev. 97, 207-281 (1997). https://doi.org/10.1021/cr941181o

11. M. Suriya, M. Mani Maran, B. MiltonBoaz, B. Gunasekaran, S. Kalainathan, K. Sakthi Murugesan, Crystal growth, structural, optical and piezoelectric investigations on novel B4AAT (bis-4-acetylanilinium tartrate): a phase matchable second and third-order NLO single crystal for optoelectronic and nonlinear optical device applications. Opt. Mater. 108, 110042 (2020). https://doi.org/10.1016/j.optmat.2020.110042

12. M. Rajkumar, A. Chandramohan, synthesis, growth, characterisation and laser damage threshold studies of $\mathrm{N}$, $\mathrm{N}$-dimethylanilinium-3-carboxy-4-hydroxybenzensulphonate crystal: an efficient SHG material for electro-optic applications. Opt. Mater. 66, 261-270 (2017). https://doi.org/10.10 16/j.optmat.2017.02.022

13. V. Krishnakumar, G. Eazhilarasi, R. Nagalakshmi, M. Piasecki, I.V. Kityk, P. Bragiel, Field-induced non-linear optical features of p-aminoazobenzene crystals. Eur. Phys. J. Appl. Phys. 42, 263-267 (2008). https://doi.org/10.1051/epjap: 2008056 
14. G. Anandh Babu, P. Ramasamy, Synthesis, crystal growth and characterization of novel semiorganic nonlinear optical crystal: Dichlorobis(1-proline)zinc(II). Mater. Chem. Phys. 113, 727-733 (2009). https://doi.org/10.1016/j.matchemphys.200 8.08 .041

15. A. Rajeswari, G. Vinitha, P. Murugakoothan, Investigation on optical, thermal, mechanical, dielectric and ferroelectric properties of non linear optical single crystal guanidinium manganese sulphate. J. Mater Sci. Mater Electron. 29, 12526-12535 (2018). https://doi.org/10.1007/s10854-018-93 $52-1$

16. K. Senthilkumar, K. Thirumoorthy, G. Vinitha, K. Soni, N.S.P. Bhuvanesh, N. Palanisami, Synthesis and characterization of $\mathrm{d}^{10}$ metal complexes of 3-Me-5-FcPz: Structural, theoretical and third order nonlinear optical properties. J. Mol. Struct. 1128, 36-43 (2017). https://doi.org/10.1016/j.mol struc. 2016.08 .036

17. A. Subashini, K. Poornima Priyadharsani, K. Thamaraiselvi, H. Stoeckli-Evans, G. Bhagavannarayana, K. Ramamurthi, R. Ramesh Babu, J. Mater Sci. Mater Electron. 29, 4147-4154 (2017). https://doi.org/10.1007/s10854-017-8359-3

18. M.A. Fersi, I. Chaabane, M. Gargouri, A. Bulou, Structure and characterization of the phase transition of the new organiinorganic hybrid compound $\left[\mathrm{C}_{8} \mathrm{H}_{10} \mathrm{NO}\right]_{2}\left[\mathrm{ZnCl}_{4}\right]$. Polyhedron 85, 41-47 (2015). https://doi.org/10.1016/j.poly.2014.08.056

19. J.V. Jovita, K. Boopathi, P. Ramasamy, A. Ramanand, P. Sagayaraj, Synthesis, growth and characterization of 4-methyl anilinium phenolsulfonate single crystal. J. Cryst. Growth 380, 218-223 (2013). https://doi.org/10.1016/j.jcrysgro.2013. 06.027

20. M.J. Frisch, G.W. Trucks, H.B. Schlegel, G.E. Scuseria, M.A. Robb, J.R. Cheeseman, G. Scalmani, V. Barone, B. Mennucci, G.A. Petersson, H. Nakatsuji, M. Caricato, X. Li, H.P. Hratchian, A.F. Izmaylov, J. Bloino, G. Zheng, J.L. Sonnenberg, M. Hada, M. Ehara, K. Toyota, R. Fukuda, J. Hasegawa, M. Ishida, T. Nakajima, Y. Honda, O. Kitao, H. Nakai, T. Vreven, J.A. Montgomery, Jr., J.E. Peralta, F. Ogliaro, M. Bearpark, J.J. Heyd, E. Brothers, K.N. Kudin, V.N. Staroverov, R. Kobayashi, J. Normand, K. Raghavachari, A. Rendell, J.C. Burant, S.S. Iyengar, J. Tomasi, M. Cossi, N. Rega, J.M. Millam, M. Klene, J.E. Knox, J.B. Cross, V. Bakken, C. Adamo, J. Jaramillo, R. Gomperts, R.E. Stratmann, O. Yazyev, A.J. Austin, R. Cammi, C. Pomelli, J.W. Ochterski, R.L. Martin, K. Morokuma, V.G. Zakrzewski, G.A. Voth, P. Salvador, J.J. Dannenberg, S. Dapprich, A.D. Daniels,O. Farkas, J.B. Foresaman, J.V. Ortiz, J. Cioslowski, and D.J. Fox. Gaussian, Inc., Wallingford, CT, 2009

21. C. Lee, W. Yang, R.G. Parr, Development of the Colle-Salvetti correlation-energy formula into a functional of the electron density. Phys. Rev. B. 37, 785-789 (1988). https://d oi.org/10.1103/PhysRevB.37.785

22. M. Saravanakumar, J. Chandrasekaran, M. Krishnakumar, B. Babu, G. Vinitha, Mohd Anis, Experimental and quantum chemical studies on SHG, Z-scan and optical limiting investigation of 2-amino-5-bromopyridinium trifluoroacetate single crystal for optoelectronic applications. J. Phys. Chem. Solides 136, 109133 (2020). https://doi.org/10.1016/j.jpcs.2019. 109133

23. C.N.R. Rao, Ultra-Violet and Visible Spectroscopy: Chemical Applications, 3rd edn. (Butterworths, London, UK, 1975).

24. M. Suriya, B. Milton Boaz, K. Sakthi Murugesan, Investigation on the growth, spectral, thermal, mechanical, electrical, laser damage threshold and third-order nonlinear optical studies of 4-acetylanilinium perchlorate (4AAPCl) semi-organic single crystal for optical limiting applications. Appl. Phys. A 125, 619 (2019). https://doi.org/10.1007/s00339-01 9-2905-1

25. K. Boopathi, S. MoorthyBabu, R. Jagan, P. Ramasamy, Synthesis, crystal structure and growth of a new inorganic organic hybrid compound for nonlinear optical applications: aquadiiodo (3-aminopropanoic acid) cadmium (II). J. Phys. Chem. Solides 111, 419-430 (2017). https://doi.org/10.1016/ j.jpcs.2017.08.038

26. S. Chennakrishnan, S.M. Ravikumar, C. Shanthi, R. Srineevasan, T. Kubendiran, D. Sivavishnu, M. Packiyaraj, Synthesis and Investigation on growth and physiochemical properties of semi-organic nonlinear optical crystal: L-glutamic acid zinc chloride. J. Taibah Univ. Sci. 11, 955-965 (2017). https://doi.org/10.1016/j.jtusci.2017.01.001

27. R. Gomathi, S. Madeswaran, Structural, thermal and nonlinear optical studies on novel organic cyclohexylammonium hydrogen adipate crystal. Mater. Chem. Phys. 218, 189-195 (2018). https://doi.org/10.1016/j.matchemphys.2018.07.051

28. R. Bhuvaneswari, M. Divya Bharathi, G. Anbalagan, K. Sakthi Murugesan, Investigation on the growth, spectral, thermal, laser and optical properties of glycinium 2-carboxy 6-nitrophthalate single crystal. Opt. Mater. 84, 728-737 (2018). https://doi.org/10.1016/j.optmat.2018.08.018

29. J. Tauc, R. Grigorovici, A. Vancu, Optical properties and electronic structure of amorphous germanium. Phys. Stat. Sol. 15, 627-637 (1966). https://doi.org/10.1002/pssb. 19660150224

30. S. Karthigha, S. Kalainathan, F. Hamada, M. Yamada, Y. Kondo, Synthesis, growth and third-order nonlinear optical properties of quinolinium single crystal-PCLQI. RSC Adv. 6, 33159-33169 (2016). https://doi.org/10.1039/C6RA05055G

31. J. Dalal, N. Sinha, H. Yadav, B. Kumar, Structural, electrical, ferroelectric and mechanical properties with Hirshfeld surface analysis of novel NLO semiorganic sodium p-nitrophenolate 
dehydrate piezoelectric single crystal. RSC Adv. 5, 57735-57748 (2015). https://doi.org/10.1039/C5RA10501C

32. P. Jayaprakash, M. Peer Mohamed, M. Lydia Caroline, Growth, spectral and optical characterization of a novel nonlinear optical organic material: D-alanine DL-mandelic acid single crystal. J. Mol. Struct. 1134, 67-77 (2017). h ttps://doi.org/10.1016/j.molstruc.2016.12.026

33. C. Rathika Thaya Kumari, M. Nageshwari, S. Sudha, M. Lydia Caroline, Growth and characterization of an efficient semi organic single crystal: sodium hydrogen oxalate monohydrate. Chinese J. Phys. 56, 2673-2683 (2018). https://doi. org/10.1016/j.cjph.2018.09.038

34. S. Jeeva, S. Muthu, S. Tamil Selvan, M. Lydia Caroline, P. Purushothaman, S. Sevvanthi, G. Vinitha, G. Mani, Growth, spectroscopic studies, and third order non-linear optical analysis of an organic dicarboxylic acid based single crystal: urea oxalic acid. Chinese J. Phys. 56, 1449-1466 (2018). h ttps://doi.org/10.1016/j.cjph.2018.05.021

35. M. Nageshwari, P. Jayaprakash, C. Rathika Thaya Kumari, G. Vinitha, M. Lydia Caroline, Growth, spectral, linear and nonlinear optical characteristics of an efficient semiorganic acentric crystal: L-valinium L-valine chloride. Phys. B 511, 1-9 (2017). https://doi.org/10.1016/j.physb.2017.01.027

36. P. Sangeetha, P. Jayaprakash, M. Nageshwari, C. Rathika Thaya Kumari, S. Sudha, M. Prakash, G. Vinitha, M. Lydia Caroline, Growth and characterization of an efficient new NLO single crystal L-phenylalanine D-methionine for frequency conversion and optoelectronic applications. Phys. B 525, 164-174 (2017). https://doi.org/10.1016/j.physb.2017.0 8.037

37. F. Urbach, The long-wavelength edge of photographic sensitivity and of the electronic absorption of solids. Phys. Rev. 92, 1324 (1953). https://doi.org/10.1103/PhysRev.92.1324

38. P. Jayaprakash, P. Sangeetha, C. Rathika Thaya Kumari, M. Lydia Caroline, Investigation on the growth, spectral, lifetime, mechanical analysis and third-order nonlinear optical studies of L-Methionine admixtured D-Mandelic acid single crystal: a promising material for nonlinear optical applications. Phys. B 518, 1-12 (2017). https://doi.org/10.1016/j.ph ysb.2017.05.017

39. M. Anbuchezhiyan, S. Ponnusamy, C. Muthamizhchelvan, K. Sivakumar, Crystal growth, structure and characterizations of a new semiorganic nonlinear optical material- $\beta$-Alanine zinc chloride. Mat. Res. Bull. 45, 897-904 (2010). https://doi.org/ 10.1016/j.materresbull.2010.04.020

40. M. Lydia Caroline, A. Kandasamy, R. Mohan, S. Vasudevan, Growth and characterization of dichlorobis L-proline $\mathrm{Zn}$ (II): a semiorganicnonlinear optical single crystal. J. Cryst. Growth 311, 1161-1165 (2009). https://doi.org/10.1016/j.jcrysgro.20 08.11 .095
41. M. Suriya, B. Milton Boaz, G. Chakkaravarthi, G. Vinitha, K. Sakthi Murugesan, Synthesis, crystal growth, structural, spectral, thermal, optical characteristics and density functional theory calculations of a novel third-order nonlinear optical material: 4-acetylanilinium dihydrogen phosphate (4AADP) single crystals. J. Mol. Struct. 1180, 330-343 (2019). https://doi.org/10.1016/j.molstruc.2018.12.001

42. B. Valarmathi, C. Amirthakumar, S. Sudhakar, G. Vinitha, R. MohanKumar, Synthesis, crystal growth, and characterization of Piperazinediium bis (4-aminobenzoate) dihydrate-an efficient third-order nonlinear optical single crystal for optoelectronic application. Chinese J. Phys. 62, 223-239 (2019). h ttps://doi.org/10.1016/j.cjph.2019.09.028

43. M. PeerMohamed, S. Sudha, P. Jayaprakash, G. Vinitha, M. Nageshwari, P. Sangeetha, C. Rathika Thaya Kumari, M. Lydia Caroline, Growth and characterization of L-histidinium fumarate fumaric acid monohydrate single crystal: A promising second and third order nonlinear optical material. Chinese J. Phys. 60, 581-597 (2019). https://doi.org/10.1016/ j.cjph.2019.05.032

44. E.M. Onitsch, The present status of testing the hardness of materials. Mikroskopie 95, 12-14 (1956)

45. H.S. Guder, E. Sahin, O. Sahin, H. Gocmez, C. Duran, H. Ali Cetinkara, Vickers and knoop indentation microhardness study of $\beta-\mathrm{Si}$ AlON ceramic. Acta Phys. Pol. A 120, 1026-1033 (2011). https://doi.org/10.12693/APhysPolA.120. 1026

46. R. Surekha, R. Gunaseelan, P. Sagayaraj, K. Ambujam, L-phenylalanine L-phenylalanimium bromide - a new nonlinear optical material. RSC Cryst. Eng. Comm. 16, 7979-7989 (2014). https://doi.org/10.1039/C4CE00718B

47. R.O.M.U. Jauhar, P. Era, V. Viswanathan, P. Vivek, G. Vinitha, D. Velmurugan, P. Murugakoothan, Crystal structure, molecular packing, FMO, NBO, nonlinear optical and optical limiting properties of an organic imidazolium diphenylacetate diphenylacetic acid single crystal. New J. Chem. 42, 2439-2449 (2018). https://doi.org/10.1039/C7NJ03693K

48. N. Durairaj, S. Kalainathan, M.V. Krishnaiah, Investigation on unidirectional growth of 1,3,5-Triphenylbenzene by Sankaranarayanan-Ramasamy method and its characterization of lifetime, thermal analysis, hardness and etching studies. Mater. Chem. Phys. 181, 529-537 (2016). https://doi.org/10. 1016/j.matchemphys.2016.06.090

49. S. Karthick, K. Thirupugalmani, M. Krishnakumar, V. Kannan, G. Vinitha, S. Brahadeeswaran, Synthesis, structural, dielectric, laser damage threshold, third order nonlinear optical and quantum chemical investigations on a novel organic crystalline material: pyrrolidin-1-ium 2-chloro-4-nitrobenzoate 2-chloro-4- nitrobenzoic acid for opto-electronic 
applications. Opt. Laser Technol. 122, 105849 (2020). http s://doi.org/10.1016/j.optlastec.2019.105849

50. P. Vivek, P. Murugakoothan, Second- and third-order optical studies of 4-Bromoanilinium hydrogen phthalate single crystal for nonlinear optical device applications. Appl. Phys. A 115, 1139-1146 (2014). https://doi.org/10.1007/s00339-0 14-8435-y

51. K. Arunkumar, S. Kalainathan, Synthesis, growth and characterization of organic nonlinear optical 3-(4-fluorophenyl)-1(4-methoxyphenyl) single crystal grown by vertical Bridgman technique. Org. Electron. 77, 105516 (2020). https://doi.org/ 10.1016/j.orgel.2019.105516

52. S.E. AllenMoses, S. Tamilselvan, S.M. Ravi Kumar, G. Vinitha, T. Ashok Hegde, M. Vimalan, S. Varalakshmi, S. Sivaraj, Synthesis, growth and physicochemical properties of new organic nonlinear optical crystal L-threoninium tartrate (LTT) for frequency conversion. Mater. Sci. Energy Technol. 2, 565-574 (2019). https://doi.org/10.1016/j.mset.2019.05. 003

53. A. Gandhimathi, R.T. Karunakaran, A. Elakkina Kumaran, S. Prabahar, Spectroscopic and quantum chemical perspectives on 2-amino 5-methylpyridinium 4-nitrobenzoate-an organic single crystals for optoelectronics device applications. Opt. Laser. Technol. 103, 291-299 (2018). https://doi.org/10.1016/ j.optlastec.2018.01.053

54. P. Karuppasamy, T. Kamalesh, K. Anitha, M.S. Pandian, P. Ramasamy, S. Verma, Design and growth of novel organic molecular Quinoline 4-nitrophenol (QNP) single crystals: for nonlinear optical (NLO) applications. J. Mol. Struct. 1210, 128036 (2020). https://doi.org/10.1016/j.molstruc.2020. 128036

55. S. Boomadevi, R. Dhanasekaran, Synthesis, crystal growth and characterization of L-pyrrolidone-2-carboxylic acid (LPCA) crystals. J. Cryst. Growth 261, 70-76 (2004). https://d oi.org/10.1016/j.jcrysgro.2003.09.010

56. V. Mathew, S. Jacob, C.K. Mahadevan, K.E. Abraham, A study of thermal, dielectric and magnetic properties of strontium malonate crystals. Phys. B 407, 222-226 (2012). h ttps://doi.org/10.1016/j.physb.2011.10.032

57. B. Babu, J. Chandrasekaran, B. Mohanbabu, Y. Matsushita, M. Saravanakumar, Growth, physicochemical and quantum chemical investigations on 2-amino 5-chloropyridinium-4carboxybutanoate - an organic crystal for biological and optoelectronic device applications. RSC Adv. 6, 110884-110897 (2016). https://doi.org/10.1039/ C6RA15791B

58. K. Syed Suresh Babu, G. Peramaiyan, M. NizamMohideen, R. Mohan, Crystal structure, growth and characterizations of semiorganic nonlinear optical (Bis) isonicotinamide perchlorate monohydrate (BINPM). J. Therm. Anal. Calorim. 120,
1337-1345 (2015). https://doi.org/10.1007/s10973-015-44578

59. F. Kremer, A. Schoenhals, Broadband Dielectric Spectroscopy (Springer, Berlin, Heidelberg, 2003). https://doi.org/ 10.1007/978-3-642-56120-7

60. M. Rajkumar, P. Muthuraja, M. Dhandapani, A. Chandramohan, Supramolecular network through N-H $\cdots \mathrm{O}$, O$\mathrm{H} \cdots \mathrm{O}$ and $\mathrm{C}-\mathrm{H} \cdots \mathrm{O}$ hydrogen bonding interaction and density functional theory studies of 4-methylanilinium-3-carboxy-4-hydroxybenzenesulphonate crystal. J. Mol. Struct. 1153, 192-201 (2018). https://doi.org/10.1016/j.molstruc.20 17.10 .013

61. M. Zgonik, R. Schlesser, I. Biaggio, E. Voit, J. Tscherry, P. Gunter, Materials constants of $\mathrm{KNbO} 3$ relevant for electroand acousto-optics. J. Appl. Phys. 74, 1287-1297 (1993). h ttps://doi.org/10.1063/1.354934

62. M. Jazbinsek, M. Zgonik, Material tensor parameters of LiNbO3 relevant for electro- and elasto-optics. Appl. Phys. B Lasers Opt. 74, 407-414 (2002). https://doi.org/10.1007/ s003400200818

63. J.D. Jackson, Classical Electrodynamics, 2nd edn. (Wiley Eastern Limited, New York, 1978).

64. D.R. Penn, Wave-number-dependent dielectric function of semiconductors. Phys. Rev. 128, 2093-2097 (1962). https://d oi.org/10.1103/PhysRev.128.2093

65. N.M. Ravindra, V.K. Srivastava, Properties of liquid PbS, PbSe and PbTe. Infrared Phys. 20, 339-418 (1980). https://d oi.org/10.1016/0020-0891(80)90058-5

66. S. Sen Gupta, N. Maiti, R. Chadha, S. Kapoor, Probing of different conformations of piperazine using Raman spectroscopy. Chem. Phys. 436-437, 55-62 (2014). https://doi. org/10.1016/j.chemphys.2014.03.011

67. M. Born, E. Wolf, Osnovy Optiki, 2nd edn. (Nauka, Moscow, 1970).

68 P. Karuppasamy, M.S. Pandian, P. Ramasamy, S. Verma, Crystal growth, structural, optical, thermal, mechanical, laser damage threshold and electrical properties of triphenylphosphine oxide 4-nitrophenol (TP4N) single crystals for nonlinear optical applications. Opt. Mat. 79, 152-171 (2018). https://doi. org/10.1016/j.optmat.2018.03.041

69 P. Karuppasamy, M.S. Pandian, P. Ramasamy, Crystal growth and characterization of third order nonlinear optical piperazinium bis(4-hydroxybenzenesulphonate) (P4HBS) single crystal. J. Cryst. Growth 473, 39-54 (2017). https://doi.org/10. 1016/j.jcrysgro.2017.05.018

70. M.S. Kajamuhideen, K. Sethuraman, K. Ramamurthi, P. Ramasamy, Crystal growth, physical properties and computational insights of semi-organic non-linear optical crystal diphenylguanidinium perchlorate grown by conventional 
solvent evaporation method. J. Cryst. Growth 483, 16-25 (2018). https://doi.org/10.1016/j.jcrysgro.2017.11.007

71. V.N. Joshi, Photoconductivity (Marcel Dekkar, New York, 1990).

72. R.H. Bube, Photoconductivity of Solids (Wiley Inter Science, New York, 1981).

73 B. Milton Boaz, S. Mary Navis Priya, J. Mary Linet, P. Martin Devaprasath, S. Jeromedas, Photoconductivity and dielectric studies on NLO active NPNa and NPLi single crystals. Opt. Mater. 29, 827-832 (2007). https://doi.org/10.1016/j.optmat. 2006.01 .006

74. H.H. Willard, L.L. Merritt Jr., J.A. Dean, F.A. Settle Jr., Instrumental Methods of Analysis, 6th edn. (D. Van Nostrand Co., New York, 1981).

75. J. Lei, C. Hou, D. Huo, Y. Li, X. Luo, M. Yang, H. Fa, M. Bao, J. Li, B. Deng, Detection of ammonia based on a novel fluorescent artificial nose and pattern recognition. Atmos. Pollut. Res. 7, 431-437 (2016). https://doi.org/10.1016/j.apr. 2015.10.019

76. G. Shanmugam, S. Brahadeeswaran, Spectroscopic, thermal and mechanical studies on 4-methylanilinium p-toluenesulfonate - a new organic NLO single crystal, Spectrochim. Acta Part A Mol. Bio-mol. Spectrosc. 95, 177-183 (2012). http s://doi.org/10.1016/j.saa.2012.04.100

77. R. Renjith, Y.S. Mary, H.T. Varghese, C. YohannanPanicker, T. Thiemann, A. Shereef, A.A. Al-Saadi, Spectroscopic investigation (FT-IR and FT-Raman), vibrational assignments, HOMO-LUMO analysis and molecular docking study of 1-hydroxy-4,5,8-tris(4-methoxyphenyl) anthraquinone. J. Phys. Chem. Solides 87, 110-121 (2015). https://doi.org/ 10.1016/j.jpcs.2015.07.024

78. K. Senthil, S. Kalainathan, Y. Kondo, F. Hamada, M. Yamada, Investigation on the crystal growth, molecular structure and nonlinear optical susceptibilities of 2-[2-(4ethoxy-phenyl)-vinyl]-1-ethyl-stibazolium iodiode (EESI) by Z-scan technique using He-Ne laser for third-order nonlinear optical applications. Opt. Laser Techno. 90, 242-251 (2017). https://doi.org/10.1016/j.optlastec.2016.10.019

79. F.J. Luque, M. Orozco, P.K. Bhadane, S.R. Gadre, SCRF calculation of the effect of hydration on the topology of the molecular electrostatic potential. J. Phys. Chem. 97, 9380-9384 (1993). https://doi.org/10.1021/j100139a021

80. P. Karuppasamy, T. Kamalesh, V. Mohankumar, S.A. Kalam, M.S. Pandian, P. Ramasamy, S. Verma, S. Venugopal Rao, Synthesis, growth, structural, optical, thermal, laser damage threshold and computational perspectives of 4-nitrophenol 4-aminobenzoic acid monohydrate (4NPABA) single crystal. J. Mol. Struct. 1176, 254-265 (2019). https://doi.org/10.1016/ j.molstruc.2018.08.074
81. A. Priyadharshini, S. Kalainathan, Structural, optical, electrical properties of new hybrid organic-inorganic NLO single crystal: bis(1H-benzotriazole) hexaaqua-zinc bis(sulfate) tetrahydrate (BZS). J. Mater. Sci.: Mater. Electron. 28, 5089-5101 (2016). https://doi.org/10.1007/s10854-016-62226

82. K. Janardhana, V. Ravindrachary, P.C. Rajesh Kumar, Y. Ismayil, Third order nonlinear optical studies of 1-(4-chloro phenyl)- 3-(4-dimethylamino phenyl) prop-2-en-1-one. J. Cryst. Growth 368, 11-20 (2013). https://doi.org/10.1016/j. jerysgro.2012.12.169

83. L. Chun-fei, S. Jin-hai, Y. Miao, W. Yu-xiao, Excited-state nonlinear absorption and its application in photonic technology. Acta Phys. Sin. 4, 569-580 (1995). https://doi.org/10. 1088/1004-423x/4/8/002

84. D. Sajan, N. Vijayan, K. Safakath, R. Philip, I.H. Joe, Intramolecular charge transfer and Z-scan studies of a semiorganic nonlinear optical material sodium acid phthalate hemihydrate: a vibrational spectroscopic study. J. Phys. Chem. A 115, 8216-8226 (2011). https://doi.org/10.1021/ jp201818y

85. P.S. Latha Mageshwari, R. Priya, S. Krishnan, V. Joseph, S. Jerome Das, Growth, optical, thermal, mechanical and dielectric studies of sodium succinate hexahydrate ( $\beta$ phase) single crystal: a promising third order NLO material. Opt. Laser Technol. 85, 66-74 (2016). https://doi.org/10.1016/j. optlastec.2016.06.002

86. T. Arivazhagan, S. Siva Bala Solanki, N.P. Rajesh, Growth and characterization of butyl 4-hydroxybenzoate single crystal by vertical Bridgman technique for third order nonlinear optical applications. Opt. Laser Technol. 88, 188-193 (2017). https://doi.org/10.1016/j.optlastec.2016.08.017

87. M. Divya Bharathi, G. Ahila, J. Mohana, G. Chakkaravarthi, G. Anbalagan, Synthesis, crystal structure, growth, optical and third order nonlinear optical studies of $8 \mathrm{HQ} 2 \mathrm{C} 5 \mathrm{~N}$ single crystal - an efficient third-order nonlinear optical material. Mater. Chem. Phys. 192, 215-227 (2017). https://doi.org/10. 1016/j.matchemphys.2017.01.087

88. J. Mohana, G. Ahila, M. Divya Bharathi, G. Anbalagan, Growth, spectral, optical, thermal, and mechanical behaviour of an organic single crystal: quinolinium 2-carboxy 6 -nitrophthalate monohydrate. J. Cryst. Growth 450, 181-189 (2016). https://doi.org/10.1016/j.jcrysgro.2016.06.044

89. Z. Zang, Y. Zhang, Analysis of optical switching in a $\mathrm{Yb}^{3+}$. doped fiber Bragg grating by using self-phase modulation and cross-phase modulation. Appl. Opt. 51, 3424-3430 (2012). h ttps://doi.org/10.1364/AO.51.003424

90. Z.-G. Zang, Y.-J. Zhang, Low-switching power $(<45 \mathrm{~mW})$ optical bistability based on optical nonlinearity of ytterbiumdoped fiber with a fiber Bragg grating pair. J. Mod. Opt. 59, 
161-165 (2012). https://doi.org/10.1080/09500340.2011. 622842

91. Z. Zang, All-optical switching in Sagnac loop mirror containing an ytterbium-doped fiber and fiber Bragg grating. Appl. Opt. 52, 5701-5706 (2013). https://doi.org/10.1364/A O.52.005701
Publisher's Note Springer Nature remains neutral with regard to jurisdictional claims in published maps and institutional affiliations. 